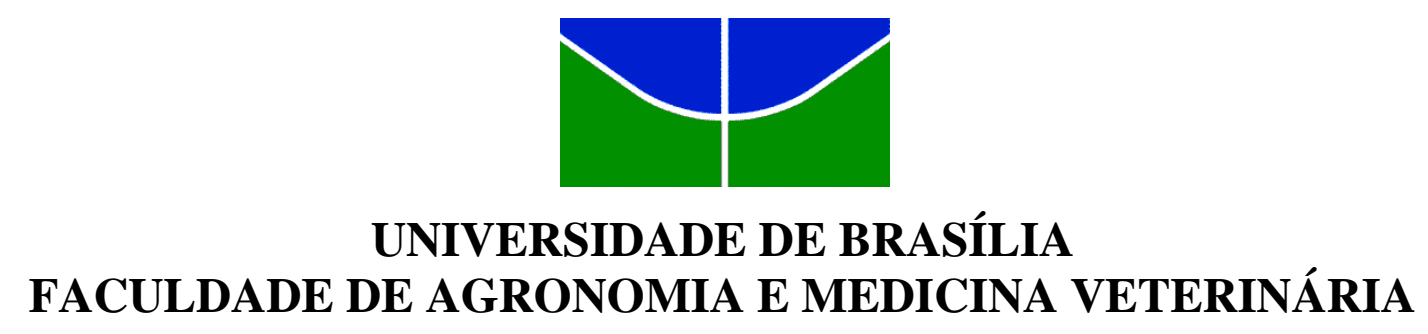

AVALIAÇÃO DE PROTOCOLOS DE INSEMINAÇÃO ARTIFICIAL EM TEMPO FIXO PARA BOVINOS CURRALEIRO PÉ-DURO

RENATO DOS SANTOS

DISSERTAÇÃO DE MESTRADO EM CIÊNCIAS ANIMAIS

BRASÍLIA/DF

FEVEREIRO DE 2016 


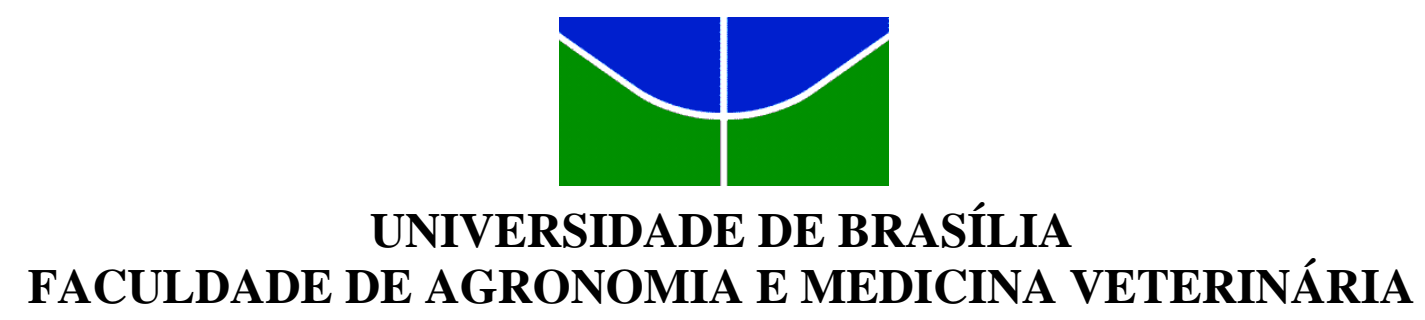

AVALIAÇÃO DE PROTOCOLOS DE INSEMINAÇÃO ARTIFICIAL EM TEMPO FIXO PARA BOVINOS CURRALEIRO PÉ-DURO

\author{
Aluno: Renato dos Santos \\ Orientador: Alexandre Floriani Ramos \\ DISSERTAÇÃO DE MESTRADO EM CIÊNCIAS ANIMAIS
}

PUBLICAÇÃO: 156/2016

BRASÍLIA/DF

FEVEREIRO DE 2016 


\section{REFERÊNCIA BIBLIOGRÁFICA E CATALOGAÇÃO}

SANTOS, R. Avaliação de protocolos de inseminação artificial em tempo fixo para bovinos Curraleiro Pé-Duro. Brasília: Faculdade de Agronomia e Medicina Veterinária, Universidade de Brasília, 2016, 62p. Dissertação de Mestrado.

Documento formal, autorizando reprodução desta dissertação de mestrado para empréstimo ou comercialização, exclusivamente pra fins acadêmicos, foi passado pelo autor à Universidade de Brasília e acha-se arquivado na Secretaria do Programa. O autor e o seu orientador reservam para si os outros direitos autorais, de publicação. Nenhuma parte desta dissertação de mestrado pode ser reproduzida sem a autorização por escrito do autor ou do seu orientador. Citações são estimuladas, desde que citada à fonte.

Ficha catalográfica elaborada automaticamente, com os dados fornecidos pelo(a) autor(a)

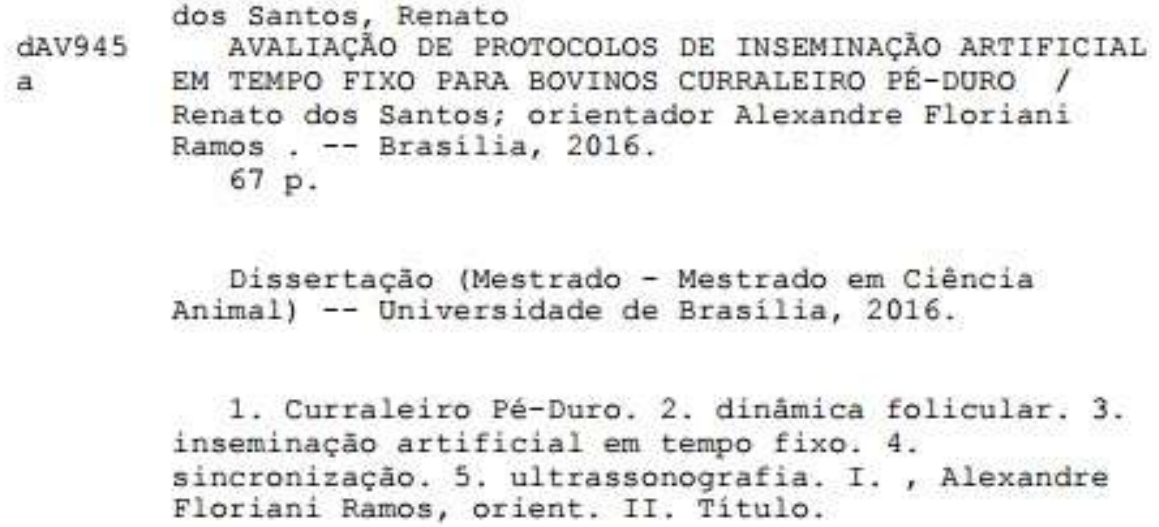


UNIVERSIDADE DE BRASÍLIA

FACULDADE DE AGRONOMIA E MEDICINA VETERINÁRIA

AVALIAÇÃO DE PROTOCOLOS DE INSEMINAÇÃO ARTIFICIAL EM TEMPO FIXO PARA BOVINOS CURRALEIRO PÉ-DURO.

RENATO DOS SANTOS

DISSERTAÇÃO DE MESTRADO SUBMETIDA AO PROGRAMA DE PÓS-GRADUAÇÃO EM CIÊNCIAS ANIMAIS, COMO PARTE DOS REQUISITOS NECESSÁRIOS À OBTENÇÃO DO GRAU DE MESTRE EM CIÊNCIAS ANIMAIS.

APROVADA POR:

ALEXANDRE FLORIANI RAMOS, DOUTORADO (EMBRAPA RECURSOS GENÉTICOS E BIOTECNOLOGIA) (ORIENTADOR)

CLAYTON QUIRINO MENDES, DOUTORADO (UNIVERSIDADE DE BRASÍLIA) (EXAMINADOR INTERNO)

MARÍLIA VIVIANE SNEL DE OLIVEIRA, DOUTORADA (UNIÃO PIONEIRA DE ENSINO) (EXAMINADORA EXTERNA)

BRASÍLIA/DF, 25 de Fevereiro de 2016. 
Aos meus pais, Edelmirio dos Santos e, Helena Casaril dos Santos pela confiança, dedicação, incentivo e trabalho para que eu tivesse mais essa oportunidade de estudo; à minha nona Zelinda (in memorian), como pedido de perdão pela minha ausência no momento em que mais precisou. 


\section{AGRADECIMENTOS}

Ao meu orientador Dr. Alexandre Floriani Ramos, pela confiança e oportunidade dadas a mim, ingressando-me no mundo da conservação animal e permitindo o desenvolvimento deste trabalho.

A toda família Maganha (Sr. Walter, João Manoel e Paulo Otávio) e aos funcionários da fazenda Coqueiro pela indispensável ajuda, receptividade e confiança depositadas em mim no decorrer de todo nosso trabalho.

À minha companheira Claudiana Alves da Silva, pelo incentivo, apoio e entendimento durante todo o mestrado.

À minha família pelo apoio, dedicação, incentivo, renúncia e amor, dedicados a mim durante todo esse período.

Ao amigo e Doutor, Rodrigo Dornelles Tortorella, pela imprescindível ajuda e por todo ensinamento a mim repassado com toda paciência e sabedoria.

Aos colegas de Pós Graduação do nosso grupo de pesquisa, Eleonora, Heitor, Nathalia, Oscar, Paula e Priscila, aos estagiários Ana Carolina e Guilherme (in memorian) pelo apoio, pelo convívio e pelas discussões no decorrer do desenvolvimento dos trabalhos.

Aos colegas e inesquecíveis amigos de alojamento, em gratidão pela convivência e distração.

A Embrapa Recursos Genéticos e Biotecnologia, especialmente aos funcionários do Campo Experimental Fazenda Sucupira: Seu Zequinha, Japão, Seu Eurípides, Teco, Manoel, Seu Arlindo e Sidnei.

Aos amigos Felippe Manoel Costa Caixeta e Severino Bernardino de Sena Netto, que dia após dia provam o verdadeiro sentido da palavra amizade quando posta em prática.

A todos que contribuíram com meu crescimento e torcem por mim, minha admiração e sincera gratidão. 


\section{ÍNDICE}

Capítulos/Subcapítulos Página

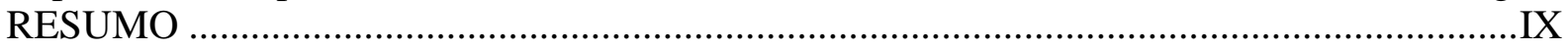

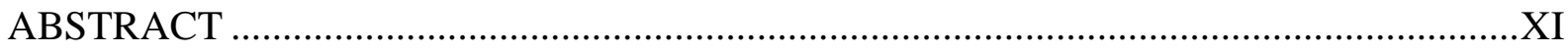

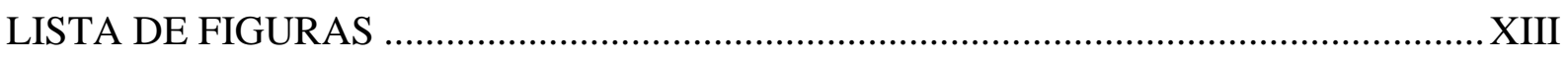

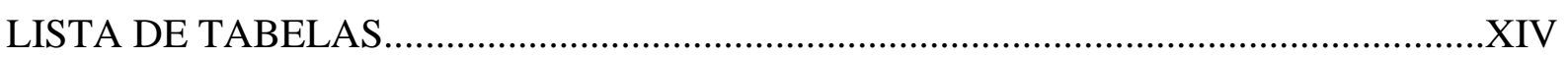

LISTA DE SÍMBOLOS E ABREVIAÇÕES .............................................................

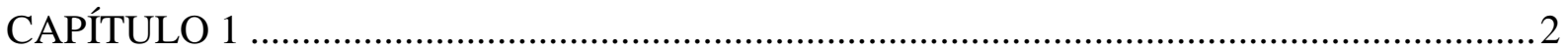

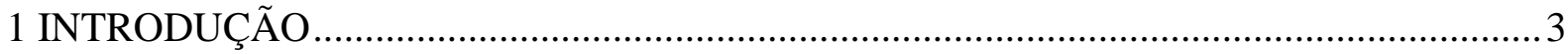

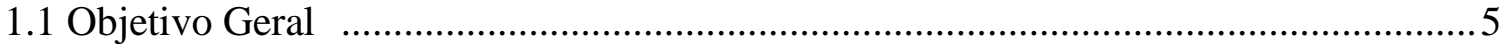

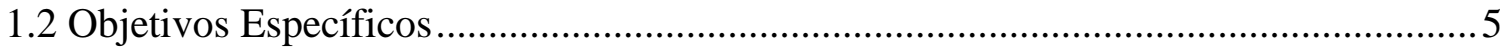

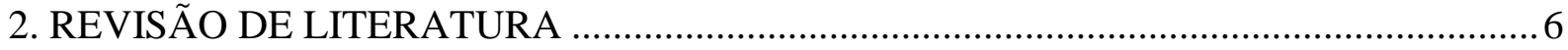

2.1 A raça de bovinos localmente adaptados Curraleiro Pé-Duro ..................................... 6

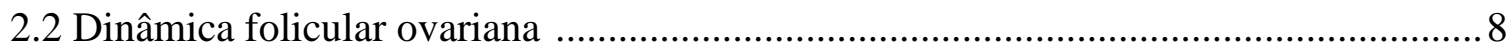

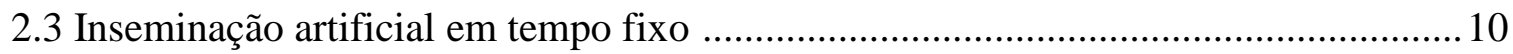

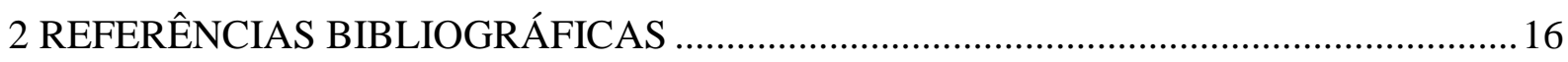

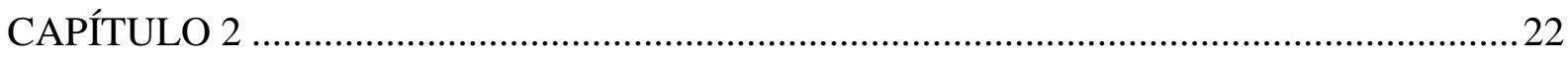

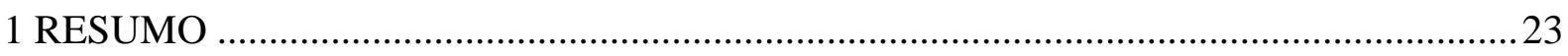

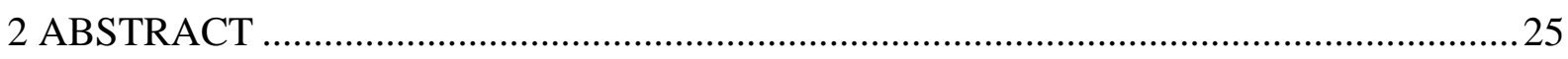

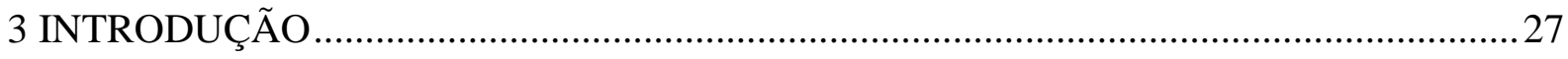

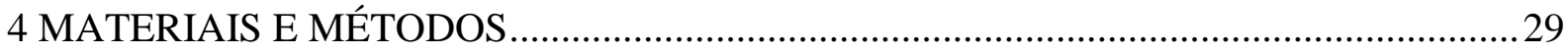

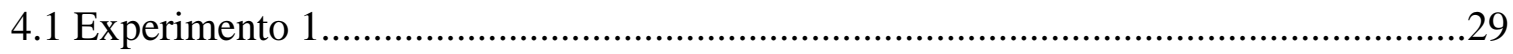

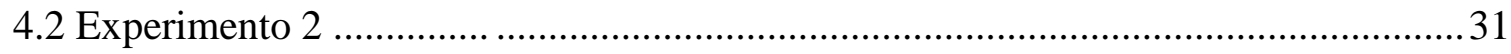

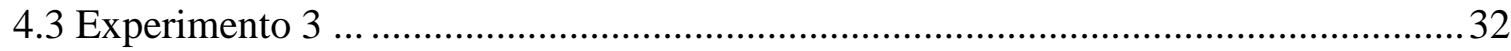

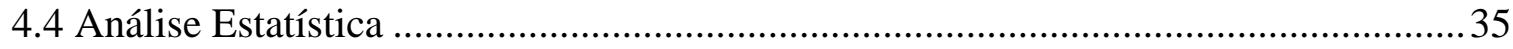

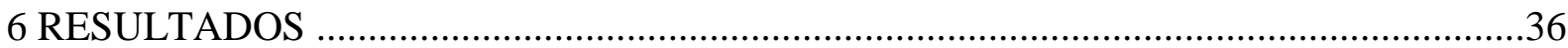

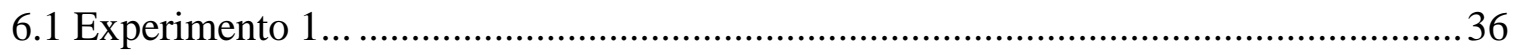

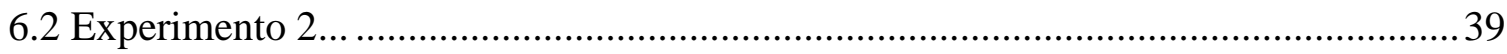

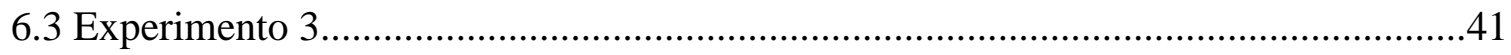

7 DISCUSSÃO

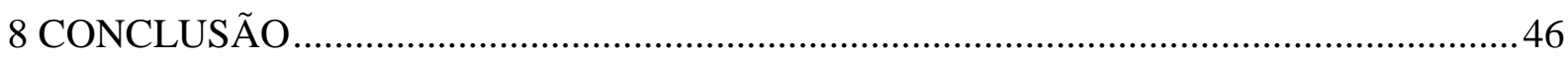

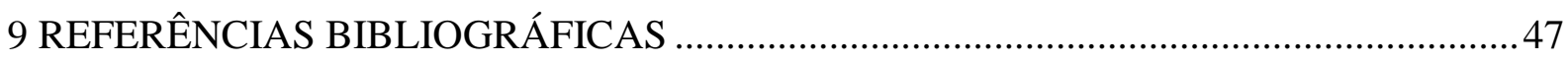

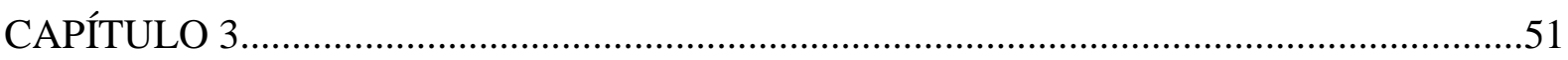


10 CONSIDERAÇÕES FINAIS. 
RESUMO

\title{
AVALIAÇÃO DE PROTOCOLOS DE INSEMINAÇÃO ARTIFICIAL EM TEMPO FIXO PARA BOVINOS CURRALEIRO PÉ-DURO.
}

\author{
Renato dos Santos ${ }^{1}$, Alexandre Floriani Ramos ${ }^{2}$ \\ ${ }^{1}$ Faculdade de Agronomia e Medicina Veterinária - UnB, Brasília-DF, ${ }^{2}$ Embrapa Recursos \\ Genéticos e Biotecnologia, Brasília-DF.
}

O estudo teve como objetivo verificar a resposta fisiológica de fêmeas da raça Curraleiro PéDuro submetidas a diferentes protocolos de sincronização e indução da ovulação, buscando-se o aumento da eficiência reprodutiva. Três experimentos foram realizados para avaliar o melhor momento de indução da ovulação e o tempo de exposição à progesterona. No Experimento 1, 12 vacas receberam um dispositivo intravaginal de progesterona $\left(\mathrm{P}_{4}\right)$ e $2 \mathrm{mg}$ de benzoato de estradiol (BE) intramuscular (IM) no dia zero (D0). Após oito dias (D8) os animais tiveram o implante de $\mathrm{P}_{4}$ removido e receberam $150 \mu \mathrm{g}$ de D-cloprostenol Sódico (PGF2 $\alpha$ ) e 300 UI de gonadotrofina coriônica equina (eCG) via IM, sendo então separadas em dois grupos. Grupo 8D (n=6), as vacas receberam 1mg de BE IM no D8, e no grupo 9D (n=6), receberam BE no D9. No Experimento 2, cinco vacas foram submetidas ao mesmo protocolo usado no Grupo 9D do Experimento um, e seis vacas no D8 receberam $150 \mu \mathrm{g}$ de PGF2 $\alpha$ e 300 UI de eCG e no D9 receberam $1 \mathrm{mg}$ de $\mathrm{BE}$ e tiveram o dispositivo de $\mathrm{P}_{4}$ retirado (Grupo P4D9). Em ambos os experimento, após a retirada do implante de $\mathrm{P}_{4}$ foram realizadas avaliações ovarianas ultrassonográficas. No Experimento 3, 88 matrizes foram submetidas aos protocolos utilizados nos grupos $8 D(n=43)$ e P4D9 $(n=45)$ e inseminadas em tempo fixo. No 
Experimento 1, os grupos 8D e 9D levaram a uma taxa de sincronização do folículo dominante de $92 \%(11 / 12)$ e $83 \%$ (10/12) e uma taxa de ovulação de $73 \%$ (8/11) e 100\% (10/10), respectivamente. O tempo para ovulação após a retirada da $\mathrm{P}_{4}$ foi menor nas fêmeas do 8D. No Experimento 2, os grupos 9D e P4D9, levaram a uma taxa de sincronização do folículo dominante de $72 \%$ (8/11) e 100\% (11/11), respectivamente e a uma taxa de ovulação de $87,5 \%$ (7/8) e 91\% (10/11), não havendo diferença nos demais parâmetros foliculares estudados. No experimento 3, a taxa de gestação nos grupos 8D e P4D9 foram de 23\% $(10 / 43)$ e $20 \%(9 / 45 ; \mathrm{P}>0,05)$ respectivamente. Conclui-se que, os protocolos utilizados neste trabalho tiveram resultados de desenvolvimento folicular satisfatórios, mas não refletiram em uma boa taxa de prenhes após inseminação artificial em tempo fixo (IATF). Nesse contexto, há necessidade de mais estudos em relação à fisiologia reprodutiva das fêmeas Curraleiro PéDuro e quanto à aplicação de protocolos de IATF para animais desta raça.

Palavras chave: Curraleiro Pé-Duro, dinâmica folicular, inseminação artificial em tempo fixo, sincronização, ultrassonografia. 


\begin{abstract}
INSEMINATION PROTOCOLS OF ARTIFICIAL EVALUATION IN FIXED TIME FOR CATTLE CURRALEIRO PÉ-DURO

\author{
Renato dos Santos ${ }^{1}$, Alexandre Floriani Ramos ${ }^{2}$ \\ ${ }^{1}$ School of Agronomy and Veterinary Medicine - UnB, DF, ${ }^{2}$ Embrapa Genetic Resources and \\ Biotechnology, Brasilia-DF
}

The study aimed to determine the physiological response breed females Curraleiro Pé-Duro subjected to different synchronization protocols and ovulation induction, searching for a increase in the reproductive efficiency. Three experiments were conducted to evaluate the best time of ovulation induction and the time of exposure to progesterone. In experiment 1,12 cows received an intravaginal progesterone device $\left(\mathrm{P}_{4}\right)$ and $2 \mathrm{mg}$ estradiol benzoate $(\mathrm{EB})$ intramuscular (IM) on day zero (D0). After eight days (D8) the animals had implants removed and $\mathrm{P}_{4}$ received $150 \mu \mathrm{g}$ of D-cloprostenol Sodium (PGF2 $\alpha$ ) and 300 IU of equine chorionic gonadotropin (eCG) IM then being separated into two groups. 8D group $(n=6)$, cows received $1 \mathrm{mg}$ of EB IM in D8, and 9D ( $\mathrm{n}=6)$ group received BE in D9. In experiment 2, five cows were subjected to the same protocol used in the group 9D from the experiment one, and six cows in D8 received $150 \mu \mathrm{g}$ of PGF2a and 300 IU of eCG and D9 received $1 \mathrm{mg}$ EB and had 
the removed $\mathrm{P}_{4}$ device (P4D9 group). In both experiments, after the withdrawal of $\mathrm{P}_{4}$ implant was performed ovarian ultrasonographic evaluation. In Experiment 3, 88 matrices were submitted to the protocols used in the groups 8D $(n=43)$ and P4D9 $(n=45)$ and inseminated at fixed time. In experiment 1 , the groups $8 \mathrm{D}$ and 9D led to a sync rate of the dominant follicle $92 \%(11 / 12)$ and $83 \%(10 / 12)$ and ovulation rate of $73 \%(8 / 11)$ to $100 \%(10 / 10)$, respectively. The time to ovulation after removal of $\mathrm{P}_{4}$ was lower in females from $8 \mathrm{D}$. In the second experiment, the 9D and P4D9 groups, led to a sync rate of the dominant follicle $72 \%(8 / 11)$ and $100 \%(11 / 11)$, respectively, and an ovulation rate of $87,5 \%$ (7/8) and 91\% (10/11), with no difference in the other follicular parameters studied. In the third experiment, the pregnancy rate in 8D and P4D9 groups were 23\% (10/43) and 20\% (9/45; P>0.05) respectively. In conclusion, the protocols used in this study had satisfactory follicular development results, but not reflected in a good rate of pregnant after artificial insemination in fixed time (TAI). In this context, there is need for more studies on the reproductive physiology of Curraleiro Pé-Duro females and on the application of TAI protocols for animals of this breed.

Keywords: Curraleiro Pé-Duro, follicular dynamics, artificial insemination in fixed time, synchronization, ultrasonography. 


\section{LISTA DE FIGURAS}

Figura

Página

\section{Capítulo 1}

Figura 1.1 Exemplares de fêmeas localmente adaptadas da raça Curraleiro PéDuro.

\section{Capítulo 2}

Figura 1.2 Protocolos utilizados para o delineamento experimental referentes ao experimento 1.

Figura 1.3 Protocolos utilizados para o delineamento experimental referentes ao experimento 2.

Figura 1.4 Fêmeas da Raça Curraleiro Pé-Duro que passaram pelo programa de IATF.

Figura 1.5 Protocolos utilizados para o delineamento experimental referentes ao experimento 3 .

Figura 1.6 Padrão de comportamento do FD após a colocação da $\mathrm{P}_{4}$.

Figura 1.7 Taxa de sincronização do FD para os tratamentos 8D e 9D.

Figura 1.8 Taxa de ovulação das fêmeas submetidas aos tratamentos 8D e 9D.

Figura 1.9 Taxa de sincronização do FD para os tratamentos 9D e P4D9.

Figura 2.0 Taxa de ovulação das fêmeas submetidas aos tratamentos 9D e P4D9.

Figura 2.1 Taxa de gestação das fêmeas submetidas aos protocolos de inseminação artificial em tempo fixo para os grupos tratamentos $8 \mathrm{D}$ e P4D9. 


\section{LISTA DE TABELAS}

Tabela

Página

\section{Capítulo 2}

Tabela 1 Características avaliadas (média \pm DP) mediante exames ultrassonográficos em fêmeas da raça localmente adaptada Curraleiro Pé-Duro, para o experimento 1.

Tabela 2 Características avaliadas (média \pm DP) mediante exames ultrassonográficos em fêmeas da raça localmente adaptada Curraleiro Pé-Duro, para o experimento 2. 


\section{LISTA DE SÍMBOLOS E ABREVIAÇÕES}

$>$ - maior

$<-$ menor

\pm- mais ou menos

$\geq-$ maior ou igual

$\geq-$ menor ou igual

$\sim$ - aproximadamente

$\%$ - porcentagem

BE - Benzoato de estradiol

$\mathrm{CE}$ - Cipionato de estradiol

CEUA - Comitê de Ética no Uso Animal

CL - corpo lúteo

$\mathrm{D}-\operatorname{dia}$

Dl - diâmetro longitudinal

Dt - diâmetro transversal

DF - Distrito Federal

DP - desvio padrão

E2 - estradiol

ECC - escore de condição corporal

FD - Folículo dominante

FO - Folículo ovulatório

FSH - Hormônio Folículo Estimulante

GnRH - Hormônio Liberador de Gonadotrofinas

GO - Goiás

$\mathrm{h}-$ horas

IA - Inseminação artificial

IATF - Inseminação artificial em tempo fixo

IM - Intramuscular 
INSA - Instituto Nacional do Semiárido

LH - Hormônio Luteinizante

$\mu \mathrm{g}-$ micrograma

mg - miligramas

$\mathrm{MHz}$ - Mega Hertz

$\mathrm{mL}-$ mililitros

mm - milímetro

n - número de amostras

$\mathrm{P}_{4}$ - Progesterona

PGF2 $\alpha$ - Prostaglandina-F2 alfa

$\mathrm{r}-$ raio

US - Ultrassom

USDA - United States Department of Agriculture

V - volume

VE - Valerato de estradiol 


\section{CAPÍTULO 1}




\section{INTRODUÇÃO}

A preservação dos recursos genéticos animais e a conservação das raças bovinas localmente adaptadas para uso futuro é tarefa minuciosa e importantíssima, onde, as características de adaptação, resistência e rusticidade do bovino Curraleiro Pé-Duro, tendem, num futuro bem próximo, serem incorporadas à bovinocultura nacional. A produção do Curraleiro Pé-Duro no cenário nacional de produção apresenta-se inviável, contudo, à medida que o crescimento populacional aumenta, tal ferramenta de produção tornar-se-á indispensável principalmente por seu potencial de produção para regiões geograficamente desfavoráveis por condições adversas de clima, onde a utilização da inseminação artificial em tempo fixo (IATF) entrará como ferramenta extremamente vantajosa no intuito de padronização e caracterização deste rebanho.

Os protocolos utilizados para a inseminação artificial em tempo fixo embasamse nos conhecimentos até hoje compreendidos da função fisiológica do ciclo estral da fêmea. O controle do desenvolvimento folicular em todas as suas fases se dá pela estratégica farmacológica com uso de hormônios específicos, o que torna possível o domínio exógeno do ciclo folicular ovariano. Contudo, há particularidades referentes à função reprodutiva da raça Curraleiro Pé-Duro que deve ser levado em consideração, na tentativa de buscar a eficiência destes em programas de sincronização e inseminação artificial com tempo pré-determinado.

De forma generalizada, Baruselli et al., (2004) enfatizam que a manipulação do ciclo estral baseia-se em alterações na sequência cronológica das ondas foliculares dentro de um ciclo estral e ainda, dentro das fases presentes em cada onda de crescimento folicular. O estudo a respeito da fisiologia reprodutiva possibilitou a manipulação do ciclo estral de forma contínua, trazendo em si, consequências visíveis e ao mesmo tempo positivas para a eficiência reprodutiva do rebanho bovino nas mais diversas modalidades de produção pecuária a nível mundial (Binelli et al., 2006).

Neste sentido, adotaram-se determinadas estratégias farmacológicas em protocolos de tratamentos hormonais, dentro de uma sequência pré-definida para efeitos 
específicos e diretos na dinâmica folicular ovariana (Binelli et al., 2006; Baruselli et al., 2006). Contudo, apesar de todo avanço nas biotecnologias voltadas à reprodução animal ainda constatam-se relatos referentes às baixas taxas de serviço decorrentes da ineficiência, principalmente na detecção do estro em vacas, e nesse contexto, no sentido de otimizar o manejo e ao mesmo tempo minimizar ao máximo a mão-de-obra, foram desenvolvidos protocolos de sincronização da ovulação permitindo que as fêmeas possam ser inseminadas em horários pré-estabelecidos (Vasconcelos et al., 2006).

Conforme dados do United States Department of Agriculture (USDA, 2014), o Brasil possui o maior rebanho comercial do mundo, estando em primeiro lugar no ranking mundial de exportação de carne bovina, ocupando o segundo posto de maior produtor de carne e sexto maior produtor de leite a nível mundial. Desta forma, a viabilidade econômica da pecuária encontra-se diretamente vinculada à eficiência reprodutiva das fêmeas para a produção de bezerros, sendo, a IATF uma ferramenta de ampla efetividade para a bovinocultura nacional. 


\subsection{Objetivo Geral}

Observar a resposta fisiológica das fêmeas Curraleiras Pé-Duro na tentativa de aumentar a eficiência de protocolos de sincronização e indução da ovulação para inseminação artificial em tempo fixo em fêmeas localmente adaptadas da raça Curraleiro Pé-Duro.

\subsection{Objetivos Específicos}

Verificar a resposta ovulatória das fêmeas da raça Curraleiro Pé-Duro submetidas aos diferentes protocolos de indução da ovulação;

Avaliar o desenvolvimento folicular de vacas da raça Curraleiro Pé-Duro frente a utilização de diferentes protocolos de sincronização e indução da ovulação;

Avaliar o tamanho do folículo ovulatório e estimar o tempo para ovulação nos diferentes protocolos utilizados nas fêmeas da raça Curraleiro Pé-Duro;

Avaliar a taxa de prenhes de fêmeas da raça Curraleiro Pé-Duro submetidas a diferentes protocolos de sincronização e indução da ovulação. 


\section{REVISÃO DE LITERATURA}

\subsection{A raça localmente adaptada de bovinos Curraleiro Pé-Duro}

Considerado uma reserva genética, o Curraleiro Pé-Duro vem de uma seleção natural de cinco séculos, evoluindo e trazendo características próprias de adaptação e resistência às condições brasileiras, apresentando aptidão para ocupar diversas áreas de climas desfavoráveis a outras raças (Mariante \& Egito, 2002).

O Curraleiro Pé-Duro apresenta características raciais bastante singulares (Figura1.1), quando comparados aos animais de raças comerciais, dentre elas, peso mínimo de $380 \mathrm{~kg}$ e altura mínima de 1,34 m para os machos e $300 \mathrm{~kg}$ e 1,20 m para as fêmeas adultas; a pelagem varia de baia a vermelha clara, sendo as extremidades como vassoura da cauda e focinho, pretos, podendo alguns exemplares apresentar manchas escuras ao redor dos olhos. Apresenta cornos curtos a médios em forma de coroa com orelhas pontudas, pequenas e revestidas com pelagem clara em uma cabeça relativamente pequena. Apresenta barbela e umbigo curtos além de membros delgados (Santin, 2008).

Desenvolvido principalmente no semiárido nordestino e nas regiões de cerrado do estado de Goiás e Tocantins, a raça Curraleiro Pé-duro apresenta-se hoje em reduzido número de exemplares (Boaventura, 2005). A perda de espaço na cadeia de produção da pecuária nacional pelo advento das raças comerciais melhoradas está minimizando cada vez mais a ascensão do mesmo no cenário atual de produção bovina (Teixeira, 2009). 
Trabalhos desenvolvidos em parceria entre órgãos governamentais, associações de criadores e empresas particulares, o tentam livrar da ameaça de extinção. O programa de conservação de recursos genéticos animais criado pela Embrapa, atua de forma a evitar que a raça perca ainda mais espaço, conservando esse inestimável material genético que traz características de adaptação e resistência às diversas condições brasileiras e cuja extinção representará uma perda irreparável para o meio científico, principalmente pelas inúmeras informações contidas na sua estrutura genética (Serrano, 2001; Mariante \& Cavalcante, 2000).

Mesmo sofrendo restrição alimentar por determinados períodos, o Curraleiro Pé-Duro tem a capacidade de sofrer pouca alteração orgânica, mantendo a condição corporal e recuperando-se positivamente sem necessidade de investimentos com suplementação alimentar ou tratamentos farmacológicos específicos (Bianchini et al. 2006).
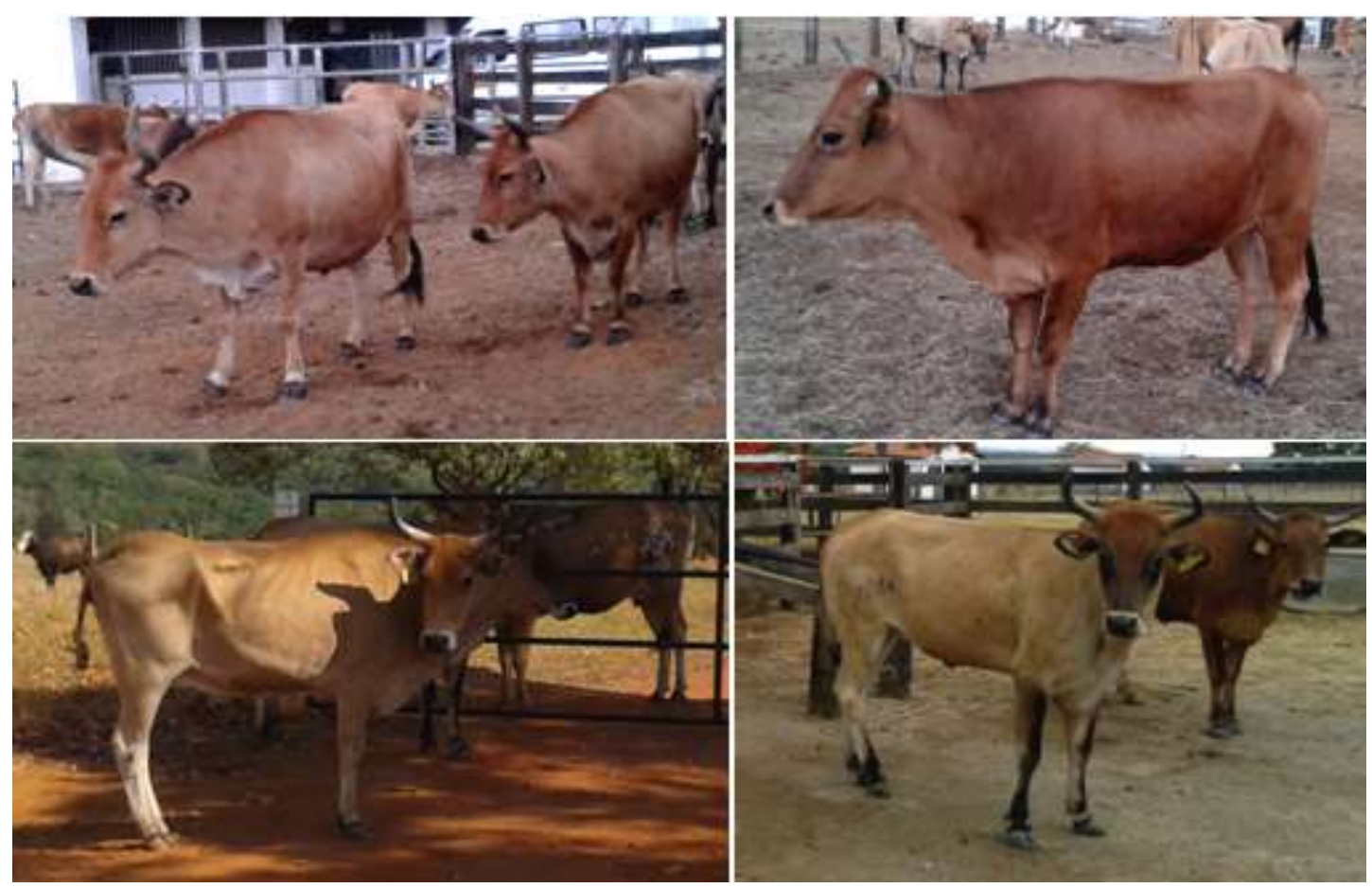

Figura 1.1. Exemplares de fêmeas localmente adaptadas da raça Curraleiro Pé-Duro.

A manutenção dessa raça rústica que dispensa de atenção integral, com características de resistência principalmente a doenças parasitárias, com restringido gasto e uso de antibioticoterapia, desempenham um papel chave no cenário produtivo, principalmente para produtores menos favorecidos seja por clima ou financeiramente (Lage, 2006).

Após praticamente ser extinto, gradativamente, o gado Curraleiro Pé-Duro passa a ganhar um espaço cada vez maior nas regiões Centro-Oeste, Norte e Nordeste do Brasil, porém, apesar das inúmeras vantagens relacionadas à criação das raças "locais", ainda 
são poucos os estudos a cerca das características reprodutivas e produtivas destes animais o que se torna ponto chave para a inserção destes na pecuária comercial brasileira. $\mathrm{O}$ desenvolvimento de biotecnologias voltadas à reprodução torna-se como meio crucial para torná-lo meio de lucratividade para pequenos e médios produtores rurais de regiões de período seco intenso.

\subsection{Dinâmica Folicular Ovariana}

A atividade cíclica ovariana está relacionada a um complexo mecanismo coordenado pelo sistema nervoso central que controla todo o funcionamento do aparelho reprodutivo da fêmea (Senger, 2003). A descrição do mecanismo fisiológico do ciclo estral bovino feita no decorrer dos anos promoveu todo o embasamento científico fundamental para que se pudesse ter controle endócrino sobre a funcionalidade do ovário, permitindo o entendimento e a manipulação exógena do ciclo ovariano de forma ampla e racional (Martinez et al., 2000; Moore \& Thatcher, 2006).

As diferentes respostas ao hormônio folículo estimulante (FSH) e ao hormônio luteinizante (LH) norteiam toda a mecânica que regula a dinâmica folicular ovariana, sendo o aumento periódico nas concentrações de FSH circulante o grande responsável pela emergência das ondas foliculares, contudo, um feedback negativo é detectado à medida que os folículos selecionados crescem e liberam o estradiol $\left(E_{2}\right)$ e inibina, impedindo assim a emergência de nova onda de desenvolvimento folicular (Bó et al., 1995).

O aumento do FSH no início do desenvolvimento folicular é o responsável por permitir o crescimento de alguns folículos até que os mesmos adquiram capacidade de resposta aos estímulos do LH. Quando ocorre uma diferença no perfil de crescimento entre o folículo dominante (FD) e os subordinados tem-se caracterizado a fase de seleção folicular e as concentrações de FSH sofrem um declínio rápido e estratégico, fato que permite que o FD expresse seus receptores ao LH, garantindo sua sobrevida de forma independente ao FSH e dependente do LH, que, com aumento pulsátil em sua frequência acelera o crescimento deste folículo, que liberará altas concentrações de estrógeno $\left(\mathrm{E}_{2}\right)$ induzindo o pico final de LH responsável pela sua ovulação (Bó et al., 2000).

Percebe-se durante um ciclo estral, a ocorrência de duas ou três ondas de desenvolvimento folicular com maior prevalência de três ondas em vacas sob presença de 
maiores concentrações de progesterona $\left(\mathrm{P}_{4}\right)$ durante a fase luteínica do ciclo (Sartori et al., 2004). Próximo de ovular, o folículo passa por mudanças funcionais e estruturais, que atuarão na formação de um corpo lúteo (CL) com capacidade de produzir $\mathrm{P}_{4}$ de forma crescente e em quantidades suficientes para garantir a manutenção de uma futura gestação, e caso a mesma não ocorra, o CL sofrerá lise e em contrapartida consequencial, o declínio plasmático da concentração de $\mathrm{P}_{4}$ (Seneda et al., 2008).

É evidente em cada onda de crescimento, os processos de recrutamento, seleção e dominância folicular onde, o FD de uma onda tem por destino fisiológico préprogramado a regressão ou a ovulação, ambos, fatores dependentes diretos do meio dominado ou não pela $\mathrm{P}_{4}$ (Bó et al., 2000). À medida que o processo de luteólise se concretiza, o FD se depara com ambiente final ideal para seu crescimento, culminando assim, com a ovulação e por vez, caso não haja a fertilização desse ovócito, o ciclo se repetirá novamente dentro de um período médio de 21 dias (Mapletoft et al., 2008).

Cada onda de crescimento folicular, é constituída por folículos de diâmetro médio entre 4 a $5 \mathrm{~mm}$ e a medida que há o processo seleção de um FD, este passa por multiplicação das células presentes na camada granulosa e reorganização estrutural das células tecais, e dentro desse processo, os folículos então subordinados entrarão em processo de regressão (Seneda et al., 2008). De forma geral, fisiologicamente o ciclo estral se divide em duas grandes fases, a fase estrogênica ou dominada pelo $E_{2}$, compreendida em pró-estro e estro e a outra, a fase progesterônica ou dominada pela $\mathrm{P}_{4}$, compreendida em metaestro e diestro (Albuquerque et al., 2004). A fase do proestro na vaca é onde, entre os dias 15 e 17 do ciclo, ocorre a secreção endometrial de Prostaglandina $\mathrm{F} 2_{\alpha}\left(\mathrm{PGF} 2_{\alpha}\right)$, contanto que este período encontre-se sob ausência de um embrião viável (Tanikawa et al., 2005), culminando com a redução significativa dos níveis basais de $\mathrm{P}_{4}$ (Vasconcelos, 2000).

$\mathrm{O}$ aumento de $\mathrm{E}_{2}$ produzido pelo folículo pré-ovulatório estimula via feedback positivo a liberação pulsátil do hormônio liberador de gonadotrofinas $(\mathrm{GnRH})$ à nível de hipotálamo, ativando a secreção do FSH e LH pela hipófise, preparando o aparelho reprodutor da fêmea para as condições específicas de um período dominado pelo $\mathrm{E}_{2}$ (Albuquerque et al., 2014). Nesta fase, o comportamento característico de estro demonstrado pela fêmea relacionase ao aumento da concentração do $\mathrm{E}_{2}$ produzido pelas células da camada granulosa do folículo ovulatório (FO), fazendo com que a mesma apresente receptividade à monta (Hafez, 2004). O pico pré-ovulatório de $E_{2}$ presente no estro, proporciona uma série de alterações no $\mathrm{FO}$ 
culminando com a ovulação deste ovócito em um período médio de 28 a 32 horas após o início da condição de estro (Sartori, 2007).

Dentro da fisiologia ovariana, a dinâmica folicular representa um dos aspectos mais importantes, sendo bastante estudada principalmente para as raças taurinas (Badinga et al., 1994). É sabido da diferença existente na fisiologia reprodutiva das vacas zebuínas para as vacas taurinas (Coutinho et al., 2007), estando estas diferenças relacionadas às características de área de tecido luteal, capacidade de secreção do LH, alterações comportamentais na detecção de cio e duração do estro, diâmetro folicular na divergência e diâmetros do folículo dominante (Barros et al., 1995; Pinheiro et al., 1998). Por mais que haja uma inter-relação específica entre os hormônios responsáveis por todo esse processo, fatores nutricionais, ambiental, de raça e idade, podem interferir negativamente no dinamismo do ciclo folicular (Lucy et al., 1992).

Com o objetivo de caracterizar a dinâmica folicular de fêmeas Curraleiras PéDuro criadas em um ambiente de clima tropical seco, Tortorella (2014), em experimento, constatou que as fêmeas apresentaram em sua maioria dois padrões de ondas foliculares, duas $(36,8 \%)$ e três $(63,2 \%)$, não havendo diferença na duração do ciclo estral entre estes. Nos animais com três ondas, a fase de dominância, taxa de crescimento e diâmetro máximo do segundo folículo dominante e o número de folículos nesta onda foram menores em relação aos outros. Ainda, os animais com três ondas, apresentaram taxa de crescimento $(1,2 \pm 0,1$ $\mathrm{mm} / \mathrm{d}$ vs $0,8 \pm 0,1 \mathrm{~mm} / \mathrm{d}$ ) e máximo diâmetro do folículo ovulatório (FO; 13,1 \pm 0,3 mm vs $12,1 \pm 0,2 \mathrm{~mm}$ ) maiores quando relacionados aos com duas ondas, respectivamente. $\mathrm{O}$ desenvolvimento do CL não diferiu entre os animais com duas e três ondas, contudo, diferenças na dinâmica folicular de animais com duas e três ondas foram encontradas, sendo algumas destas características foliculares semelhantes aos animais taurinos e zebuínos.

Desta forma, o conhecimento das diferenças se torna fundamental para o estabelecimento de novas tecnologias no intuito de aumentar o desempenho reprodutivo desses animais e consequentemente os índices zootécnicos dos rebanhos bovinos (Hahn, 1992; Fortune, 1993; Adams, 1994).

\subsection{Inseminação artificial em tempo fixo - IATF}


A inseminação artificial (IA) de bovinos ainda é considerada um dos principais avanços das últimas décadas dentro das biotecnologias aplicáveis à reprodução animal o que garante consideráveis ganhos genéticos aos mais diversos tipos raciais dos rebanhos bovinos (Barbosa \& Machado, 2008).

Desde 2008 a IA vem apresentando um crescente aumento no Brasil, isso se deve principalmente à tentativa de atender aos padrões de mercado, levando à profissionalização do setor e a busca pela rentabilidade na pecuária, explicando o crescimento do uso desta tecnologia, especialmente com o advento da inseminação artificial em tempo fixo (IATF; Inácio, 2010). Por mais que a IA propriamente dita, seja baseada simplesmente na deposição mecânica do sêmen no aparelho reprodutor da fêmea (Mies Filho, 1987), ainda a produção de carne no Brasil é sustentada pela monta natural como forma convencional de reprodução (Inácio, 2010).

É perceptível que as tecnologias aplicadas à reprodução animal vêm contribuindo de forma significativa para o melhoramento genético, mas ainda, nacionalmente, a técnica é subutilizada e apresenta pouca aplicação, seja por limitações impostas por falhas na detecção do estro, puberdade tardia ou longo período de anestro pós-parto (Sá Filho et al., 2008). Contudo, a obtenção de dados precisos de fecundação e parto, a seleção de animais do rebanho, garantindo a homogeneidade dos lotes pela utilização de poucos reprodutores em grande número de vacas, possibilitando a escolha adequada de touros visando reduzir principalmente os problemas de parto em novilhas estão entre as grandes vantagem da IA (Asbia, 2010).

Nos últimos anos o desenvolvimento de tratamentos visando à indução ou sincronização do estro e da ovulação tem ganhado grande destaque na pecuária, onde, o emprego farmacológico permitiu a sincronização do ciclo estral, a luteólise e a ovulação em tempo pré-determinado sem riscos à fertilidade das fêmeas tratadas (Sá Filho et al., 2008; Barros, 2007). A sincronização do ciclo estral baseia-se no controle do desenvolvimento da onda folicular, prevenindo a ovulação precoce e causando a luteólise em vacas cíclicas, promovendo a ovulação de fêmeas em anestro, sincronizando o estro e a ovulação ao final do tratamento (Lucy et al., 2004).

A eliminação da necessidade de observação do cio e a concentração de mão de obra necessária para o trabalho são sem dúvidas as grandes vantagens dos programas de IATF (Baruselli, 2004), porém, a viabilidade econômica da técnica entra como maior limitante, sendo algumas situações o custo benefício não favorável principalmente quando se refere aos 
fármacos utilizados (Galvani, 2009). O uso de protocolos para a IATF tem colaborado para a difusão da técnica de IA em todo tipo de rebanho e a nível mundial, possibilitando o aprimoramento genético e consequente aumento de produção (Baruselli et al., 2009).

Os implantes de $\mathrm{P}_{4}$ utilizados em protocolos de IATF agem fundamentalmente de duas maneiras principais, uma delas, é inibindo o desenvolvimento de um CL para as fêmeas que ovularam próximo a data da sua colocação e outra, bloqueando a ovulação caso esta esteja ao final do ciclo de desenvolvimento folicular (Odde, 1990). Se o dispositivo de $\mathrm{P}_{4}$ for implantado na ausência de um CL este, provocará a formação de um FD persistente com produção de um ovócito de baixa qualidade, ocasionado pela alta frequência e baixa amplitude do padrão de secreção do LH, característico da fase folicular, e não um padrão de alta amplitude e baixa frequência, como observado na fase de diestro, e tais feitos acabam prolongando a mantença do FD, e logo, interrompendo o padrão normal do crescimento em ondas (Smith \& Stevenson, 1995).

O mecanismo de maturação ovocitária é desencadeado por esse padrão de secreção, contudo, o mesmo é insuficiente para promover a ovulação, a qual somente será possível quando a administração da $\mathrm{P}_{4}$ for interrompida (Baruselli et al., 2002; Rajamanhenderan \& Taylor, 1991). Os produtos a base de $\mathrm{P}_{4}$, permanecem no interior da vagina da fêmea por um período determinado mantendo alta a concentração de $\mathrm{P}_{4}$ e em contrapartida bloqueando a liberação endógena do $\mathrm{LH}$, simulando a fase luteínica do ciclo estral (Baruselli et al., 2002). Por outro lado, a $\mathrm{P}_{4}$ não suprime a secreção de FSH, permitindo com isso, que o desenvolvimento folicular em ondas (Adams et al., 1992).

No intuito de evitar a persistência folicular, o principal objetivo dos tratamentos hormonais utilizados é a regressão do folículo dominante (Tortorella, 2010). Tal feito pode ser alcançado pela associação dos progestágenos aos derivados do 17- $\beta$ estradiol levando à regressão do folículo dominante, recrutamento, seleção e dominância em nova onda de crescimento folicular, culminando com uma ovulação apta à fecundação (Bó et al. 1995). Em virtude de o tratamento ser por curto período de tempo entre 7 ou 8 dias, a incidência de folículos persistente é reduzida e a fertilidade após a IA equipara-se à de um ciclo de desenvolvimento sem manipulação (Mapletoft et al., 2009).

Os fármacos a base de estrógenos utilizados em programas de IATF, fisiologicamente estão distribuídos por todo organismo do animal, tendo como principal ponto de acumulação o tecido adiposo e eliminação a via de metabolismo hepático. Na combinação com veículos oleosos, os estrógenos apresentam uma rápida absorção e dependendo do tipo 
de éster de estradiol utilizado, essa absorção pode se prolongar por alguns dias a parti da data de sua aplicação por via intramuscular (IM) (Bó et al., 2006).

O valerato de estradiol (VE), o cipionato de estradiol (CE) e o benzoato de estradiol (BE) são os estrógenos esterificados mais utilizados na área de reprodução animal. A esterificação do grupo hidróxilo do $17-\beta$ estradiol atua como mecanismo de proteção deste grupo ao ataque imediato do metabolismo, prolongando seu efeito sistêmico e quando relacionados uns com os outros, o CE, tem sua atividade biológica mais prolongada em relação aos outros estrógenos (10 a 12 dias), o VE meia vida variando de 7 a 9 dias e o Benzoato de Estradiol meia vida mais curta, em torno de 3 dias (Bó et al., 2006).

$\mathrm{O}$ efeito dos estrógenos, BE e 17- $\beta$ estradiol $\left(\mathrm{E}_{2}\right)$, sobre o desenvolvimento folicular é ocasionar a supressão de FSH, e a liberação de LH (Bó et al., 1994). O BE está entre os ésteres de $\mathrm{E}_{2}$ mais utilizados para a sincronização da ovulação, principalmente pela indução do pico pré-ovulatório de LH pelo mecanismo de feedback positivo sobre a liberação do GnRH e LH, quando administrado em ausência de concentrações plasmáticas de $\mathrm{P}_{4}$ (Hanlon et al., 1996).

Foi demonstrado por Bó et al (1993) que o tratamento com $\mathrm{E}_{2}$ no início dos protocolos de sincronização, ocasiona a supressão do crescimento folicular antral, sendo essa supressão bem mais profunda quando este é associado a um dispositivo liberador de $\mathrm{P}_{4}$, ampliando o mecanismo de controle induzido por este estrógeno sobre o crescimento folicular mediante a supressão de FSH. De tal forma, a associação do $\mathrm{E}_{2}$ com a $\mathrm{P}_{4}$ no início do tratamento hormonal para sincronização provoca a atresia do FD e logo, em aproximadamente 4 dias após sua administração, induz a emergência de uma nova onda de crescimento folicular, estimulando também, a secreção de PGF2 $\alpha$ atuante direta sobre a lise do CL (Bó et al., 1995; Mapletoft, 2009).

Em 24 horas após a remoção do implante de $\mathrm{P}_{4}$, uma dose mais baixa de $\mathrm{E}_{2}$ é administrada, induzindo um pico de LH entre 16 e 18 horas, culminando com uma ovulação num período de 24 a 32 horas mais tarde (Mapletoft et al., 2003). Dentro deste parâmetro, a IATF será realizada 30 horas mais tarde quando o BE for aplicado 24horas após a retirada da $\mathrm{P}_{4}$ ou será feita 48 horas após se aplicado no dia da retirada do implante de $\mathrm{P}_{4}$ (Ayres et al., 2008). Caso opte-se pelo uso do CE, se leva em consideração que o mesmo após aplicação, ocasiona o pico de LH por volta de 30 a 35 horas e a consequente ovulação em 55 horas após sua aplicação IM (Geary et al., 2001), sendo que, a IATF será realizada de 48 a 60 horas após (Sá Filho et al., 2009). 
O corpo lúteo ou CL é definido como uma glândula ovariana endócrina de caráter temporário que tem como principal função a secreção de $\mathrm{P}_{4}$, responsável pela preparação do útero para o início e manutenção de uma gestação (Siqueira et al., 2009). Se por algum motivo não houver uma gestação, a ausência embrionária permitirá a secreção endometrial e liberação da PGF2 $\alpha$ naturalmente, desencadeando uma série de eventos irreversíveis no CL, fazendo com que perca a capacidade de produzir e secretar a $\mathrm{P}_{4}$ (Trevisol et al., 2013).

As prostaglandinas (PGEs e PGFs) atuam em inúmeras funções reprodutivas na fêmea, desde a luteólise até a ovulação, no reconhecimento materno da gestação, além de serem secretadas pelo endométrio da vaca durante todo o ciclo estral, apenas com modificações no padrão de secreção ao longo deste (Waite et al., 2005). A PGF2 $\alpha$ produzida pelo endométrio no ciclo folicular alcança a circulação venosa uterina por meio de mecanismo contracorrente, passando para o sistema arterial ovariano induzindo sua vasoconstrição, isquemia e consequente luteólise por anóxia (Cunninghan, 2004).

Fisiologicamente entre os dias 15 e 17 do ciclo estral, tem-se o período crítico de início da luteólise, nessa fase ocorre significativo aumento nas secreções endometriais de PGF2 $\alpha$ quando na ausência do reconhecimento materno da gestação (Tanikawa et al., 2005). Caso haja o estabelecimento de uma gestação, percebe-se a ação conjunta das prostaglandinas E1 e E2 que desempenham funções importantes na manutenção do CL, evitando a queda das concentrações de $\mathrm{P}_{4}$, além de prevenirem a conversão da PGE2 em PGF2 $\alpha$ (Weems et al., 2010; Ginther et al., 2010).

As rápidas alterações observadas no padrão de secreção da $\mathrm{P}_{4}$ durante $\mathrm{o}$ mecanismo de luteólise apresentam-se de forma individualizada não estando acompanhadas por modificações no CL, sendo estas modificações percebidas somente após 12 horas, quando constata-se o CL com redução de $50 \%$ de seu volume (Acosta \& Miyamoto, 2004). Nos bovinos, o CL possui receptores específicos para $\mathrm{PGF} 2 \alpha$, e a ligação aos receptores na membrana das células luteais esteroidogênicas estimula a atividade da proteína quinase $\mathrm{C}$, que age interrompendo a produção de $\mathrm{P}_{4}$ pela diminuição na captação e transporte do colesterol para o citoplasma e mitocôndria das células, provocando uma retroalimentação negativa dos receptores de LH e ativação de proteínas de apoptose (Waite et al., 2005).

Outro hormônio utilizado em programas de IATF é a gonadotrofina coriônica equina (eCG), um hormônio produzido especificamente pelos cálices endometriais de éguas prenhes entre os dias 40 a 130 de gestação (Hafez, 2004). O eCG, apresenta meia vida 
relativamente longa e devido ao seu alto peso molecular tem a sua filtração glomerular dificultada, aumentando ainda mais a sua meia vida ( \pm 3 dias), em ação, fisiologicamente ligase aos receptores de FSH e LH dos folículos e de LH do CL (Stewart e Allen, 1981). Em equinos, o hormônio eCG causa ovulação e luteinização de folículos durante a gestação, com consequente aumento da produção e secreção da $\mathrm{P}_{4}$ durante a gestação das éguas (Murphy e Martinuk, 1991).

O efeito benéfico do tratamento com eCG em protocolos de IATF se dá através da estimulação do crescimento do folículo dominante e maturação, resultando na ovulação de um ovócito com alta viabilidade fecundante e formação de um CL com produção de $\mathrm{P}_{4}$ aumentada, viabilizando assim, a manutenção de uma gestação (Baruselli et al., 2004).

Atualmente há disponível no mercado, Inúmeros produtos para uso em protocolos de IATF, bem como diferentes protocolos que podem ser utilizados. Contudo, a escolha destes, deve ser equiparada ao programa reprodutivo individual das propriedades, levando em consideração a situação sanitária do rebanho, na tentativa de maximizar os resultados positivos por esta prática. 


\section{REFERÊNCIAS BIBLIOGRÁFICAS}

ACOSTA T.J, MIYAMOTO A. Vascular control of ovarian function: ovulation, corpus luteum, formation and regression. Animal Reproduction Science, v.82, p.127-140, 2004.

ADAMS, G.P. Control of ovarian follicular wave dynamics in cattle: implication for synchronization \&superstimulation. Theriogenology, v.41, p.19-24, 1994.

ADAMS, G.P.; MATTERI, R.L.; GINTHER, O.J. The effect of progesterone on growth of ovarian follicles, emergence of follicular waves and circulating FSH in heifers.J. Reprod. Fertil. 95:627-640. 1992.

AYRES, H.; MARTINS, C.M.; FERREIRA, R.M. et al. Effect of timing of estradiol benzoate administration upon synchronization of ovulation in suckling Nelore cows (Bos indicus) treated with a progesterone-releasing intravaginal device. Animal Reproduction Science, v.109, p.77-87, 2008.

ASBIA - Associação Brasileira de Inseminação Artificial. Relatório estatístico de produção, importação e comercialização de sêmen, 2010.

BADINGA, L.; THATCHER, W.W.; WILCOX, C.J. et al. Effect of season on follicular dynamics and plasma concentrations of estradiol-17 $\beta$, progesterone and luteinizing hormone in lactating holstein cows. Theriogenology, v.42, p.1263-1274, 1994.

BARBOSA, R.T.; MACHADO, R. Panorama da inseminação artificial em bovinos. Documentos 84. Embrapa Pecuária Sudeste. São Carlos. 2008.

BARROS, M.P. O Impacto da IATF no desenvolvimento da pecuária brasileira. Revista AG Leilões, n.109, 2007.

BARROS, C.M.; FIGUEIREDO, R.A.; PINHEIRO, O.L. Estro, ovulação e dinâmica folicular em zebuínos. Rev. Bras. Reprod. Anim., v.19, p.9-22, 1995.

BARUSELLI, P.S.; TONIZZA, N. A.; JACOMINI, J. O. Eficiência do uso da inseminação artificial em bubalinos. Revista Brasileira de Reprodução Animal, Belo Horizonte, n. 6, Supl., p104-110, 2009. 
BARUSELLI, P.S.; AYRES, H.; SOUZA, A.H. et al. Impacto da IATF na eficiência reprodutiva em bovinos de corte.Simpósio Internacional de Reprodução Animal Aplicada, 2, 2006, Londrina. Anais... São Paulo: VRA-FMVZ, p. 113-132. 2006.

BARUSELLI, P.S.; REIS, E.L.; GONÇALVES. et al. Manual prático de inseminação artificial em tempo fixo, Curitiba: Biogenesis do Brasil Ltda., p. 56, 2004.

BARUSELLI, P.S.; REIS, E.L.; MARQUES, M.O. et al. The use of hormonal treatments to improve reproductive performance of anestrous beef cattle in tropical climates. AnimReprodSci, 82/83:479-486. 2004.

BARUSELLI, P.S.; MARQUES, M.O.; CARVALHO, N.A.T. et al. Efeito de diferentes protocolos de inseminação artificial em tempo fixo na eficiência reprodutiva de vacas de corte lactantes. Rev. Bras. Reprod. Animal, v. 26, p. 218-221, 2002

BERTAN C.M, BINELLI M, MADUREIRA E.H. et al. Mecanismos endócrinos e moleculares envolvidos na formação de corpo lúteo e na luteólise - revisão de literatura. Braz J Vet Res AnimSci, v.43, p.824-840, 2006.

BIANCHINI, E.; MCMANUS, C.; LUCCI, C.M. et al. Características corporaisassociadas com aadptaçao ao calor em bovinos naturalizados brasileiros.Pesq. Agrop. Bras., Brasilia, v41, p.1443-1449, 2006.

BINELLI M., IBIAPINA B.T. \& BISINOTTO R.S. Bases fisiológicas, farmacológicas e endócrinas dos tratamentos de sincronização do crescimento folicular e da ovulação. Acta ScientiaeVeterinariae. 34 (Supl 1): 1-7. 2006.

BÓ, G.A.; COLAZO, MG.; MARTINEZ, M.F. et al. Sincronizacion de la emergência de la onda folicular y laovulacion em animales tratados com progestagenos y diferentes ésteres de estradiol. In: SIMPÓSIO INTERNACIONAL DE REPRODUÇÃO ANIMAL APLICADA, 2., 2006, Londrina. Anais...Londrina, p. 71-84. 2006.

BÓ, G.A.; CUTAIA, L.; CHESTA, P. et al.; BARUSELLI, P.S. Application of fixed-time artificial insemination and embryo transfer programs in beef cattle operations. In: Proceedings of the Joint Convention of AETA and CETA, Minneapolis, MN, USA. Savoy, IL: AETA. pp. 37-59. 2005.

BÓ, G. A.; ADAMSN, G.P.; MAPLETOFT, R.J. Exogenous control of follicular wage emergence in cattle. Theriogenalogy, v. 43, p. 31-40, 1995.

BÓ, G.A.; ADAMS, G.P.; CACCIA, M. et al. Ovarian follicular wave emergence after treatment with progestogen and estradiol in cattle. Anim. Reprod. Sci., v. 39, n.3, p.193204, 1995.

BÓ, G.A.; CACCIA, M.; MARTINEZ, M. et al. The use of estradiol-17 $\beta$ and progestogen treatment for the control of follicular wave dynamics in beef cattle. Theriogenology, v.40, p.165, 1994. 
BÓ, G.A.; ADAMS, G.P.; NASSER. L.F. et al. Effect of estradiol valerate on ovarian follicles, emergence of follicular waves and circulating gonadotropins in heifers.Theriogenology, 40:225-239. 1993.

BOAVENTURA, V.M. Gado Curraleiro: relação dos criadores e aspectos gerais da raça. Goiânia: Sebrae - GO, 80p. 2005.

BRASIL. Ministério da Ciência Tecnologia e Inovação. Estado atual de conservação da raça bovina curraleiro pé-duro na região nordeste brasileira / Patricy Andrade Salles...[et al.].-- Campina Grande: INSA/MCTI (Documentos Técnicos/Instituto Nacional do Semiárido, no 3) 27p. 2013.

COUTINHO, G.T.R.M.; VIANA, J.H.M.; SÁ, W.F. et al. Ultrasonographic evaluation of follicular dynamics and luteal function in Guzerá cows. Arq. Bras. Med. Vet. Zootec.v.59, n.5, p.1089-1096, 2007.

CUNNINGHAM J.G. Tratato de fisiologia veterinária. 3.ed. Rio de Janeiro: Guanabara Koogan, 2004.

FIGUEIREDO, R.A.; BARROS, C.M.; PINHEIRO, O.L. et al. Ovarian follicular dynamics in Nelore breed (Bosindicus) cattle. Theriogenology, v.47, p.1489-1505, 1997.

FORTUNE, J.E. Follicular dynamics during the bovine estrous cycle: A limiting factor in improvement of fertility? Anim. Reprod. Sci., v.33, p.111-125, 1993.

GALINA, C. S.; ORIHUELA, A.; BUBIO, I. Behavioral trends affecting oestrus detection in zebu cattle. Animal Reproduction Science, Amsterdam, v. 42, p. 465-470, 1996.

GALVANI, F. Manejo reprodutivo em gado de corte em regime de monta natural e inseminação artificial. Revista Brasileira de Reprodução Animal, Belo Horizonte, n.6, Supl., p.111-117, 2009.

GEARY, T.W.; WHITTIER, J.C.; HALLFORD, D.M. et al. Calf removal improves conception rates to the Ovsynch and COSynch protocols. Journal of Animal Science, v.79, p.1-4, 2001.

GINTHER O.J.; SHRESTHA H.K.; FUENZALIDA M.J. et al. Characteristics of Pulses of 13,14-Dihydro-15-Keto-Prostaglandin F2alpha Before, During, and after Spontaneous Luteolysis and Temporal Intrapulse Relationships with Progesterone Concentrations in Cattle. BiolReprod, v.82,p.1049-1056, 2010.

GINTHER, J. BEG, M.A.; DONADEU, F.X. et al. Mechanism of follicle deviation in monovular farm species. Animal Reproduction Science., v. 78, p. 239-257, 2003.

HAFEZ, E.S.E. Reprodução Animal. $7^{\circ}$ Ed. São Paulo: Manole, 2004.

HAHN, J. Attempts to explain and reduce variability of superovulation. Theriogenology, v.38, p.269-275, 1992. 
HANLON, D.W.; WILLIASON, N.B.; WICHTEL, J.J. et al. The effect of estradiol benzoate administracion on estrous response and synchronized pregnancy rates in dairy heifers after treatment with exogenous progesterone. Theriogenology, v.45, n.4, p. 775-85, 1996.

INÁCIO, A. Produção de carne vira foco do setor de genética bovina. Jornal Valor Econômico. Publicada em: 18/01/2010.

LAGE, A.P.; ROXO, E.; MULLER, E.E. et al. Brasil. Ministério da Agricultura, Pecuária e Abastecimento. ProgramaNacional de Controle e Erradicação da Brucelose e da Tuberculose Animal.(PNCEBT). Brasília: MAPA/SDA/DSA, 2006. 188 p. BRASIL.

LUCY, M.C. SAVIO, J.D.; BADIGNA, L. et al. Factors that effect ovarian follicular dynamics en cattle. Journal of Animal Science. v.70.p. 3615-3626. 1992.

LUCY, M.C.; MCDOUGALL, S.; NATION, D.P. The use of hormonal treatments to improve the reproductive performance of lactating dairy cows in feedlot or pasture-based management systems. Animal Reproduction Science, Amsterdam.v. 82-83, p. 495-512, 2004.

MAPLETOFT, R.J.; BÓ, G.A.; BARUSELLI, P.S. Control of ovarian function for assisted reproductive technologies in cattle. Anim. Reprod., v.6, n.1, p.114-124, Jan./Mar. 2009.

MAPLETOFT, R.J. MARTÍNEZ, M.F.; COLAZO, M.G. et al. The use for controlled internal drug release devices for the regulation of bovine reproduction. Journal of Animal Science, Champaign, v.81. Suppl.2,p. E28-E36, 2003.

MARIANTE, A.S.; EGITO, A.A. Animal Genetic Resources in Brazil: Results of Five Centuries of Natural Selection. Theriogenology, v.57, p.223-235, 2002.

MARIANTE, A. S.; CAVALCANTE, N. Animais do descobrimento: Raças domésticas da história do Brasil. Brasília, EmbrapaSede, p. 227, 2000.

MARTINEZ, M. F.; ADAMS, G. P.; KASTELIC, J. P. et al. Induction offollicular wave emergence for estrus synchronization and artificial insemination in heifers. Theriogenology, $v$. 54 , n. 5, p. 757-769, 2000.

MIES FILHO, A. Inseminação artificial. 6. ed. Sulina: Porto Alegre. v. 2, 750p, 1987.

MIYAMOTO, A.; SHARZYNSHI, D.J.; OKUDA, K. Is tumor necrone factor $\alpha$ a trigger for the initiation of endometrial prostaglandin F2 $\alpha$ release at luteolisisim cattle. BiolReprod, v.62, p.1109-1115, 2000.

MOORE, K.; THATCHER, W.W. Major advances associated with reproduction in dairy cattle. J Dairy Sci.89:1254-66; 2006.

MURPHY, B.D.; MARTINUK, S.D. Equine chorionic gonadotrophin. Endocrine Rewiews, v. 12, p. 27-44, 1991.

ODDE, K.G. A review of synchronization of estrous in postpartum cattle. J. Anim. Sci., v. 68, n.3, p. 817-30, 1990. 
PINHEIRO, O.L.; BARROS, C.M.; FIGUEIREDO, R.A. et al. Estrus behavior and the estrusto-ovulation interval in Nelore cattle (Bosindicus) with natural estrus or estrus induced with prostaglandina F2 $\alpha$ or norgestomet and estradiol valerate. Theriogenology, v.49, p.667-681, 1998.

RAJAMAHENDRAM, R.; TAYLOR, C. Follicular dynamics and temporal relationship among body temperature, oestrus, the surge of luteinizing hormone and ovulation in Holstein heifers treated with norgestome. Journal of Reproduction and Fertility , v. 92, p. 461-467, 1991.

SÁ FILHO, M. F.; GUIMENES, L. U.; SALES, J. N. S. et al. IATF emnovilha. Simpósio Internacional de Reprodução Animal Aplicada. Londrina. Anais... Londrina, p.54-67, 2008 .

SÁ FILHO, O.G.; THATCHER, W.W.; VASCONCELOS, J.L.M. Effect of progesterone and/or estradiol treatments prior to induction of ovulation on subsequent luteal lifespan in anestrous Nelore cows.Animal Reproduction Science, v.112, p.95-106, 2009.

SANTIN, A.P.I. Perfil sanitário de bovinos da raça Curraleiro frente a enfermidades de importância econômica. 2008. 78f. Tese (Doutorado em Ciência Animal), Escola de Veterinária, Universidade Federal de Goiás, Goiânia, 2008SARTORI R, HAUGHIAN JM, SHARE RD, ROSA GJ, WILTBANK MC. Comparison of ovarian function and circulating steroids in estrous cycles of Holstein heifers and lactating cows.J. Dairy Sci. v.87, p.905920, 2004.

SENEDA, M.M.; GODMANN, M.; MURPHY, B.D. et al. Developmental regulation ofhistone H3 methylation at lysine 1 in the porcine ovary. Reproduction, 135:829-38; 2008.

SENGER, P. Pathways to pregnancy and parturition. 2.ed. Washington: CurrentConceptions, 368p, 2003.

SERRANO, G. M. S. Uso de marcadores moleculares RAPD na caracterização genética das raças bovinas nativas brasileiras. 2001. 87f. Dissertação (Mestrado em Agronomia) - Faculdade de Agronomia e Medicina Veterinária, Universidade de Brasília (UNB), 2001.

SIQUEIRA, L.G.B.; TORRES, C.A.A.; AMORIM, L.S. et al. Interrelationships among morfology, echotexture, and funcion of the bovine corpus luteum during the estruscicle. AnimReprodSci, 115:18-28, 2009.

SMITH, M.W.; STEVENSON, J.S. Fate of dominant follicle, embryonal survival, end pregnancy rates in dairy cattle treated with prostaglandin F 2 and progestins in the absence on presence of a functional corpus luteun. Journal of Animal Science, v. 73, p. 3743$3751,1995$.

STEWART, F.; ALLEN, W.R. Biological functionsand receptor binding activities of equine chorionicgonadotrophins. Journal of Reproduction and Fertility, v. 62, p. 527-36, 1981. 
TANIKAWA, M.; ACOSTA, T.J.; FUKUI, T. et al. Regulation of prostaglandin synthesis by intherleukin - $1 \alpha$ in bovine endometrium during estrouscycle. Prostaglandins and Other Lipid Mediat, v.78, p.279-290, 2005.

TEIXEIRA, H.C.A. Diferentes protocolos com progesterona na resposta superestimulatória e produção embrionária em vacas do grupamento genético Curraleiro/Pé-duro. Brasília: Faculdade de Agronomia e Medicina Veterinária, Universidade de Brasília, 2009, 56p. Dissertação (Mestrado em Ciências Animais) Faculdade de agronomia e Medicina Veterinária, Universidade de Brasília, 2009.

TORTORELLA, R.D. Influência do eCG e FSHp no desenvolvimento folicular, tamanho luteal e índice de prenhez após IATF em vacas de corte lactantes. Brasília: Faculdade de Agronomia e Medicina Veterinária, 2010, 67p. Dissertação (Mestrado em Ciências Animais) - Faculdade de Agronomia e Medicina Veterinária da Universidade de Brasília, 2010 .

TREVISOL, E.; FERREIRA, J.C.P.; ACKERMANN, C.L. et al. Luteolysis in cattle: review. Rev. Bras. Reprod. Anim., Belo Horizonte, v.37, n.1, p.29-36, jan./mar. 2013.

USDA. United States Department Of Agriculture. Foreign Agricultural Service. Disponivelem<http://apps.fas.usda.gov/psdonline/>. Acesso em 12 de dezembro de 2014.

VASCONCELOS, J.L.M.; MENEGHETTI, M. \& SANTOS R.M. Inseminação artificial em tempo fixo (IATF) em bovinos. Acta Scientiae Veterinariae. 34 (Supl 1): 9-16. 2006.

WAITE, A.L.; HOLTAN, D.W.; STORMSHAK, F. Changes in bovine luteal progesterone metabolism in response to exogenous prostaglandin F2alfa. DomestAnimEndocrinol, v.28, p.162-171. 2005.

WEEMS, Y.S; NETT, T.M.; RISPOLI, L.A. et al. Prostaglandin E1 (PGE1), but notprostaglandin E2 (PGE2), alters luteal and endometrial luteinizing hormone (LH) occupied and unoccupied LHreceptors and mRNA for LH receptors in ovine luteal tissue to prevent luteolysis. Prostaglandins and Other Lipid Mediat, v.91, p.42-50, 2010. 


\section{CAPÍTULO 2}

AVALIAÇÃo DE PROTOCOLOS DE INSEMINAÇÃO ARTIFICIAL EM TEMPO FIXO PARA BOVINOS CURRALEIRO PÉ-DURO. 


\title{
1 RESUMO
}

\section{AVALIAÇÃO DE PROTOCOLOS DE INSEMINAÇÃO ARTIFICIAL EM TEMPO FIXO PARA BOVINOS CURRALEIRO PÉ-DURO.}

\author{
Renato dos Santos ${ }^{1}$, Alexandre Floriani Ramos ${ }^{1,2}$ \\ ${ }^{1}$ Faculdade de Agronomia e Veterinária - UnB, Brasília-DF, ${ }^{2}$ Embrapa Recursos Genéticos e \\ Biotecnologia, Brasília-DF.
}

Este estudo teve como objetivo verificar a resposta fisiológica de fêmeas localmente adaptadas da raça Curraleiro Pé-Duro submetidas a diferentes protocolos de sincronização e indução da ovulação, avaliando-se a eficiência destes, bem como a determinação do horário de ovulação, tamanho de folículo ovulatório, emergência da onda e por fim a taxa de gestação das fêmeas submetidas aos programas de IATF. No experimento 1, todas as fêmeas $(n=12)$ no dia zero (D0) receberam um dispositivo intravaginal contendo $1 \mathrm{~g}$ de progesterona $\left(\mathrm{P}_{4}\right)$ que permaneceu por oito dias e $2 \mathrm{mg}$ de benzoato de estradiol (BE) intramuscular (IM). Depois disso os animais foram divididos aleatoriamente em dois grupos; tratamento $8 \mathrm{D}(\mathrm{n}=6)$ e tratamento 9D $(\mathrm{n}=6)$. No dia da remoção do implante de $\mathrm{P}_{4}(\mathrm{D} 8)$ as vacas do grupo 8D receberam via IM $150 \mu \mathrm{g}$ de D-cloprostenol Sódico, 300 UI de eCG e $1 \mathrm{mg}$ de BE. No grupo tratamento 9D as vacas tiveram o implante removido no D8 e receberam via IM $150 \mu \mathrm{g}$ de Dcloprostenol Sódico e 300 UI de eCG, e em contrapartida ao grupo controle, esses animais receberam via IM no D9 $1 \mathrm{mg}$ de BE. Os tratamentos diferiram entre si, quanto ao dia de aplicação do BE. Para o experimento 2, todos os animais $(n=11)$ no D0 receberam o mesmo tratamento farmacológico do experimento anterior e foram divididos aleatoriamente em dois grupos; tratamento 9D $(n=5)$ e tratamento P4D9 $(n=6)$. Os animais do grupo tratamento 9D tiveram o implante de $\mathrm{P}_{4}$ removido no D8 e receberam via IM $150 \mu \mathrm{g}$ de D-cloprostenol Sódico e 300 UI de eCG, e no D9 receberam IM, 1 mg de BE. Em contrapartida as fêmeas do grupo tratamento P4D9 receberam no D8 por via IM $150 \mu$ g de D-cloprostenol Sódico e 300 
UI de eCG e no D9 tiveram o implante de $\mathrm{P}_{4}$ removido seguido de aplicação IM de $1 \mathrm{mg}$ de BE. Os tratamentos diferiram quanto ao tempo de retirada dos implantes de $\mathrm{P}_{4}$. Em ambos os experimento, no dia da remoção do implante de $\mathrm{P}_{4}$ também foi iniciada a avaliação ovariana ultrassonográfica a cada $24 \mathrm{~h}$, até $24 \mathrm{~h}$ após a retirada do implante de $\mathrm{P}_{4}$. Passado esse período, as avaliações ocorreram a cada $8 \mathrm{~h}$ por até 96 horas, na tentativa de monitoração do FD até a ovulação. Os experimentos 1 e 2 ocorreram no formato crossover. Para o experimento 3, utilizou-se dos protocolos referentes ao tratamento 8D e ao P4D9 para a IATF. Onde, para o grupo tratamento 8D $(n=43)$ as inseminações ocorreram no período de 40/42 hs e para o grupo tratamento P4D9 $(n=45) 24 / 26$ hs após a retirada do implante de $\mathrm{P}_{4}$. Para os experimento 1 , os tratamentos 8D e 9D levaram a uma taxa de sincronização do folículo dominante de $92 \%$ (11/12) e 83\% (10/12) e taxa de ovulação de 73\% (8/11) e 100\% (10/10), respectivamente. Não houve efeito dos tratamentos sobre o grupo e interação dia VS grupo $(\mathrm{P}>0,05)$ no desenvolvimento folicular, apenas crescimento diário $(\mathrm{P}<0,05)$. $\mathrm{O}$ momento da ovulação foi precoce no tratamento 8D. No experimento 2, os tratamentos 9D e P4D9 levaram a uma taxa de sincronização do folículo dominante de $72 \%$ (8/11) e $100 \%$ (11/11) e taxa de ovulação de $87,5 \%$ (7/8) e 91\% (10/11), respectivamente. Para ambos os experimento não ocorreu diferença no volume luteal $(\mathrm{P}>0,05)$. Já para o experimento 3, onde os animais foram submetidos à IATF, contatou-se para o grupo tratamento 8D e grupo tratamento P4D9 taxas de gestação de $23 \%$ (10/43) e 20\% (9/45) respectivamente (P>0,05), concluindo que, ainda há necessidade de mais estudos em relação à fisiologia reprodutiva das fêmeas Curraleiro PéDuro, seja pelo controle hormonal e ultrassonográfico do desenvolvimento folicular, ou pelo desenvolvimento de novas metodologias em protocolos específicos de IATF para animais desta raça.

Palavras chave: Curraleiro Pé-Duro, dinâmica folicular, inseminação artificial em tempo fixo, sincronização, ultrassonografia. 


\begin{abstract}
INSEMINATION PROTOCOLS OF ARTIFICIAL EVALUATION IN FIXED TIME FOR CATTLE CURRALEIRO PÉ-DURO
\end{abstract}

\author{
Renato dos Santos ${ }^{1}$, Alexandre Floriani Ramos ${ }^{1,2}$ \\ ${ }^{1}$ School of Agronomy and Veterinary Medicine - UnB, DF, ${ }^{2}$ Embrapa Genetic \\ Resources and Biotechnology, Brasilia-DF
}

This study aimed to determine the physiological response of locally adapted females of Curraleiro Pé-Duro breed under different synchronization protocols and ovulation induction, evaluating the efficiency of these, as well as the determination of ovulation time, ovulatory follicle size, emergency wave and finally the pregnancy rate of females submitted to TAI programs. In experiment 1 , all females $(\mathrm{n}=12)$ on day zero (D0) received an intravaginal device containing $1 \mathrm{~g}$ of progesterone $\left(\mathrm{P}_{4}\right)$ which remained for eight days and $2 \mathrm{mg}$ of estradiol benzoate (EB) intramuscular (IM). After that the animals were randomly divided into two groups; 8D treatment ( $n=6)$ and 9D treatment $(n=6)$. On removal of the implant $\mathrm{P}_{4}$ (D8) cows in the $8 \mathrm{D}$ group received IM $150 \mu \mathrm{g}$ of Sodium D-cloprostenol, $300 \mathrm{IU}$ eCG and $1 \mathrm{mg}$ of EB. In the 9D treatment group the cows had the implant removed in D8 and received IM $150 \mu \mathrm{g}$ of D-cloprostenol Sodic and $300 \mathrm{IU}$ eCG, and in contrast to the control group, the animals received IM in D9 $1 \mathrm{mg}$ EB. The treatments differed among themselves as to the $\mathrm{BE}$ application day. For the experiment 2, all animals $(n=11)$ in D0 received the same pharmacological treatment of the previous experiment and were randomly divided into two groups; 9D treatment $(n=5)$ and P4D9 treatment $(n=6)$. The animals 9D treatment group had $\mathrm{P}_{4}$ implant removed in D8 and received IM $150 \mu \mathrm{g}$ of D-cloprostenol Sodic and $300 \mathrm{IU}$ eCG, and in D9 received IM, 1mg EB. In contrast the P4D9 treatment group the females in D8 received IM $150 \mu \mathrm{g}$ of D-cloprostenol Sodium and $300 \mathrm{IU}$ eCG and in D9 were removed $\mathrm{P}_{4}$ implant followed by IM administration of $1 \mathrm{mg}$ of EB. The treatments differed on the 
withdrawal time of $\mathrm{P}_{4}$ implants. In both experiments, on the $\mathrm{P}_{4}$ implant removal day was also initiated ovarian ultrasound assessment every $24 \mathrm{~h}$ up to $24 \mathrm{~h}$ after removal of the $\mathrm{P}_{4}$ implant. After this period, the evaluations were performed every 8 hours for up to 96 hours, in the attempt to monitor from FD to ovulation. Experiments 1 and 2 occurred in crossover format. For the third experiment we used the protocols for the treatment 8D and P4D9 to TAI. Where, for the $8 D$ treatment group $(n=43)$ inseminations occurred in the period of 40/42 hours and P4D9 for the treatment group $(n=45)$ 24/26 hours after removing the implant $\mathrm{P}_{4}$. For the experiment 1 , the $8 \mathrm{D}$ and $9 \mathrm{D}$ treatments led to a sync rate of the dominant follicle of $92 \%$ $(11 / 12)$ and $83 \%(10 / 12)$ and ovulation rate of $73 \%(8 / 11)$ and $100 \%(10 / 10)$, respectively. There was no effect of treatments on group and interaction day VS group $(\mathrm{P}>0.05)$ in follicular development, only daily growth $(\mathrm{P}<0.05)$. The time of ovulation wasn't early in the 8D treatment. In the experiment 2, the treatments 9D and P4D9 led to a synchronization rate of the dominant follicle of $72 \%(8 / 11)$ and $100 \%(11 / 11)$ and ovulation rate of $87,5 \%(7 / 8)$ and $91 \%$ (10/11), respectively. For both experiment was no difference in the luteal volume $(\mathrm{P}>0,05)$. For the experiment 3 , where animals were submitted to TAI, it is found to $8 \mathrm{D}$ treatment group and P4D9 treatment group pregnancy rates of 23\% (10/43) and 20\% (9/45) respectively $(\mathrm{P}>0,05)$, concluding that there is still need for more studies on the reproductive physiology of females Curraleiro Pé-Duro, is the hormonal and ultrasonographic control of follicular development, or the development of new methodologies in TAI specific protocols for animals of this breed.

Keywords: Curraleiro Pé-Duro, follicular dynamics, artificial insemination in fixed time, synchronization, ultrasonography. 


\section{INTRODUÇÃO}

A raça Curraleiro Pé-Duro, considerada uma reserva genética, vem de uma seleção natural de cinco séculos, evoluindo e trazendo consigo características próprias de adaptação e resistência às condições brasileiras, apresentando aptidão para ocupar diversas áreas até então desfavoráveis a outras raças (Mariante \& Egito, 2002). Porém, a perda de espaço na cadeia de produção da pecuária nacional pelo advento das raças comerciais melhoradas está minimizando cada vez mais a ascensão do mesmo no cenário atual de produção pecuária (Teixeira, 2009).

Apesar das inúmeras biotecnologias relacionadas à reprodução animal para o melhoramento estarem consolidadas, torna-se necessária uma avaliação de técnicas direcionadas e eficientes à raça Curraleiro Pé-Duro a fim de frear o problema da extinção, e permitindo a viabilização da sua multiplicação (Salamanca, 2012), uma vez que, ainda pouco se conhece sobre o potencial reprodutivo da raça.

A grande variabilidade, com tratamentos hormonais até então utilizados em protocolos de sincronização do estro e ovulação na espécie bovina, resulta em diferentes taxas de fertilidade nos programas de IATF e desta forma, desenvolver protocolos de sincronização ideias, concerne o advento da raça e a consequente multiplicação da mesma no âmbito nacional de criação. 
Apesar das inúmeras vantagens relacionadas à criação das raças "locais", ainda são poucos os estudos a cerca das características reprodutivas e produtivas destes animais o que se torna fundamental para a inserção destes animais na pecuária comercial brasileira, sendo, o desenvolvimento de biotecnologias voltadas à reprodução destes, um ponto chave para torná-los meio de lucratividade para o produtor. Contudo, estudos sobre a avaliação e padronização de protocolos de IATF específicos para bovinos Curraleiros Pé-Duro ainda são necessários, levando-se em consideração os dados até hoje levantados em relação à físiologia reprodutiva destes animais. 


\section{MATERIAIS E MÉTODOS}

Todos os procedimentos descritos no trabalho foram aprovados pelo Comitê de Ética e Bem Estar Animal da Embrapa Recursos Genéticos e Biotecnologia, protocolo CEUA $02 / 2013$.

\subsection{Experimento 1}

O Experimento 1 foi realizado no Setor de Campo Experimental Fazenda

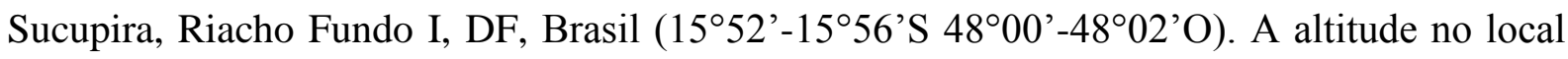
varia de 1050 a 1250 metros, sendo o clima predominante o Koppenaw, indicando inverno seco (umidade relativa pode chegar a 10\%) e verão chuvoso.

Foram utilizadas 12 fêmeas não lactantes, entre dois e seis anos, com condição corporal média 3, sendo 1 para muito magra e 5 para muito gorda (Wildman et al., 1982). Os animais foram mantidos em pastagem de Brachiaria decumbens, com suplementação mineral e acesso a água a vontade desde o início até o término do experimento. O delineamento experimental utilizado foi o crossover, onde todos os animais participaram de todos os tratamentos.

Previamente ao Experimento, todos os animais foram submetidos a exame ginecológico com palpação retal, avaliação ultrassonográfica (Mindray 2200 Vet, Shenzhen, China; equipado com probe transretal de 7,5 MHz) e vaginoscopia, minimizando assim a possibilidade de doenças ou anormalidades do aparelho reprodutivo.

No dia zero (D0) todas fêmeas receberam um dispositivo intravaginal contendo $1 \mathrm{~g}$ de progesterona $\left(\mathrm{P}_{4}\right)$ e $2 \mathrm{mg}$ de benzoato de estradiol (BE) intramuscular (IM), sendo que o implante permaneceu por oito dias. No Dia 8 as vacas receberam via IM $150 \mu \mathrm{g}$ de Dcloprostenol Sódico e 300 UI de eCG quando foram divididos aleatoriamente em dois grupos: Grupo 8D (n=6) recebendo $1 \mathrm{mg}$ de BE no Dia 8 e Grupo 9D $(\mathrm{n}=6)$ recebendo $1 \mathrm{mg}$ de BE no Dia 9 (Figura 1.2). 

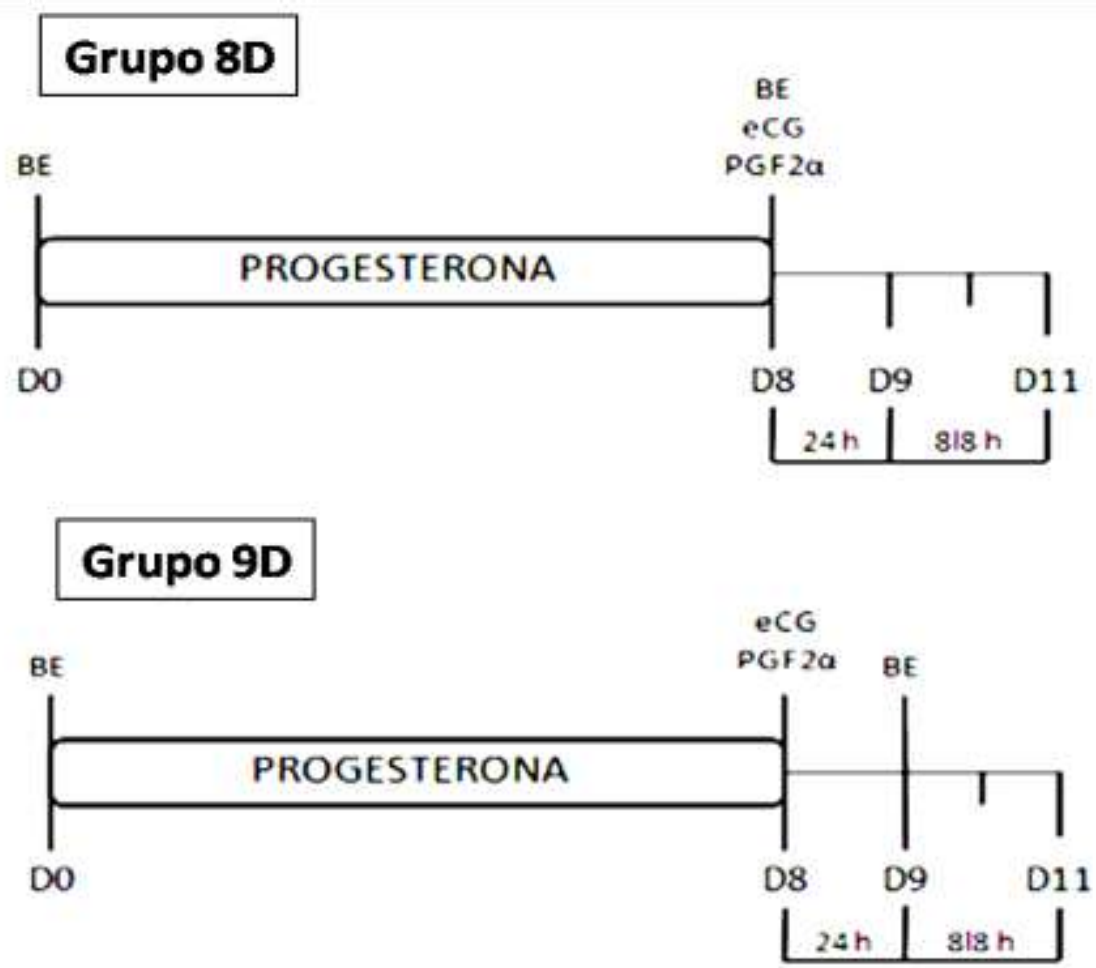

Figura 1.2. Tratamentos experimentais. Dia 0 (D0): administração de $2 \mathrm{mg} \mathrm{IM}$ de BE e inserção de dispositivo vaginal com $1 \mathrm{~g}$ de $\mathrm{P}_{4}$. Dia 8 (D8): retirada da $\mathrm{P}_{4}$ e aplicação do D-Cloprostenol Sódico (150 mg, IM), e $300 \mathrm{UI}$ de Gonadotrofina Coriônica Equina (eCG). Grupo 8D aplicação IM de $1 \mathrm{mg}$ de BE no Dia 8 (D8). Grupo 9D aplicação IM de 1 mg de BE no Dia 9 (D9).

No dia da remoção do implante de $\mathrm{P}_{4}$ (D8) foi iniciada a avaliação ovariana ultrassonográfica (Mindray 2200 Vet, Shenzhen, China; equipado com probe transretal de 7,5 $\mathrm{MHz}$ ), num intervalo de 24 horas no primeiro dia. Após o D9 as avaliações ultrassonográficas ocorreram a cada 8 h (7:00, 15:00 e 23:00 h) até 96 horas (D11) após a retirada do implante. Dez dias após a ovulação as vacas passaram por nova avaliação ultrassonográfica para mensuração do corpo lúteo (CL). Tanto os folículos e o CL foram desenhados em uma ficha de dinâmica folicular, caracterizando o tamanho e localização dos mesmos no respectivo ovário. O diâmetro folicular foi mensurado pela média de dois diâmetros perpendiculares entre eles. O dia da ovulação (Dia 0) foi determinado após o desaparecimento abrupto do FD $(\geq 9,5 \mathrm{~mm})$ entre dois exames consecutivos com formação de um CL visualizado no D10. A mensuração do volume (V) do CL foi feita após identificação dos diâmetros perpendiculares (Da e $\mathrm{Db}$ ) do mesmo. $\mathrm{O}$ volume foi calculado pela fórmula $\mathrm{V}=4 / 3 \times \pi \times \mathrm{R}^{3}$, onde $\mathrm{R}=(\mathrm{Da} / 2+$ $\mathrm{Db} / 2) / 2$. 
A emergência da onda folicular foi caracterizada pelo crescimento inicial de um grupo de folículos, em torno de 3,5 mm, sendo que, após alguns dias, um obteve maior dimensão (FD) e os outros começaram a regredir. $O$ dia da divergência folicular foi determinado pela análise retrospectiva do folículo ovulatório. Foi considerado folículo ovulatório (FO) o último folículo dominante que veio a ovular. A fase de dominância (dias) do FD foi caracterizada pelo período de crescimento e manutenção do diâmetro. A taxa de crescimento folicular $(\mathrm{mm} / \mathrm{d})$ do FD foi calculada pela razão entre a variação observada no diâmetro folicular e o número de dias de observação.

\subsection{Experimento 2}

O Experimento 2 foi realizado na Fazenda Coqueiro, localizada no Município de Pirenópolis, GO, Brasil (15 51' 09" S 48 57' 33" W). A altitude do local é de 770 metros, sendo o clima predominante o Koppenaw, indicando inverno seco (umidade relativa pode chegar a $10 \%$ ) e verão chuvoso.

Ao todo foram utilizadas 11 fêmeas, com características de condição corporal, alimentação e avaliação ginecológica, similares às dos animais submetidos ao Experimento 1. O delineamento experimental utilizado foi o crossover, onde todos os animais participaram de todos os tratamentos.

No dia zero (D0) todas fêmeas receberam um dispositivo intravaginal contendo $1 \mathrm{~g}$ de $\mathrm{P}_{4}$ e $2 \mathrm{mg}$ de BE IM. Após, os animais foram divididos aleatoriamente em dois grupos; grupo tratamento 9D $(n=5)$ e grupo tratamento P4D9 $(n=6)$. Os animais do grupo tratamento 9D, tiveram o implante de $\mathrm{P}_{4}$ removido no D8 e receberam via IM $150 \mu \mathrm{g}$ de D-cloprostenol Sódico e 300 UI de eCG, e no D9 receberam 1 mg de BE IM. Em contrapartida as fêmeas do grupo tratamento P4D9 receberam no D8 por via IM $150 \mu$ g de D-cloprostenol Sódico e 300 UI de eCG e no D9 tiveram o implante de $\mathrm{P}_{4}$ removido mediante aplicação de $1 \mathrm{mg}$ de $\mathrm{BE}$ IM. Os tratamentos diferiram quanto ao dia da retirada dos implantes de $\mathrm{P}_{4}$ (Figura 1.3). 


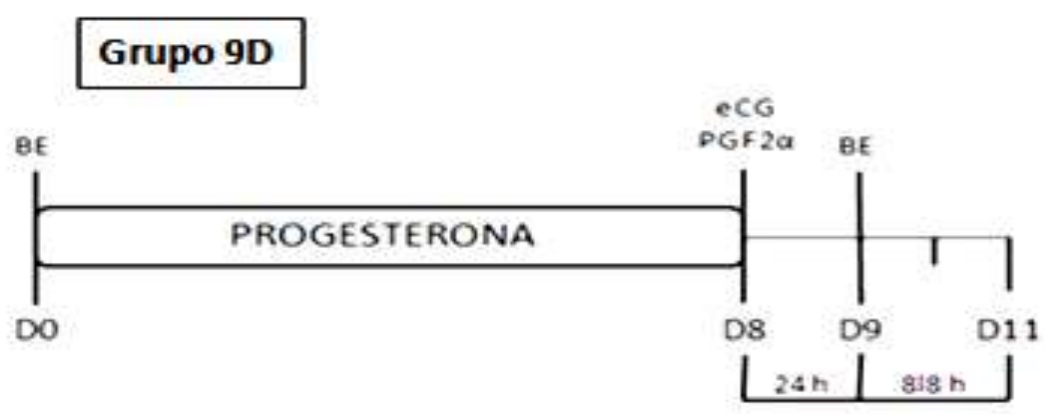

Grupo P4D9

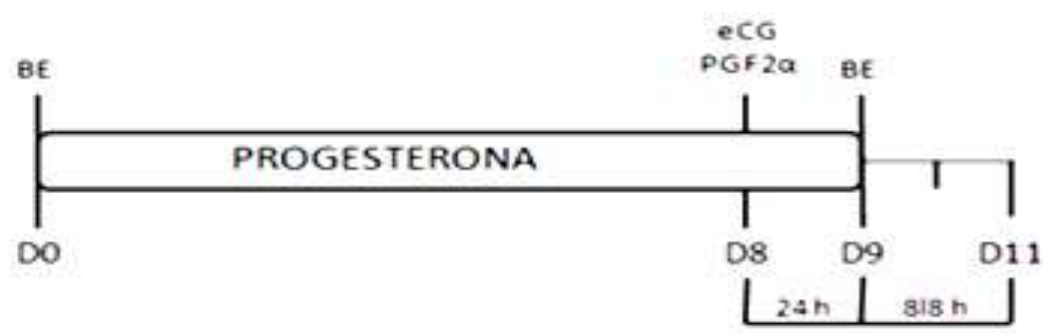

Figura 1.3. Tratamentos experimentais. Dia 0 (D0): administração de $2 \mathrm{mg}$ IM de BE e inserção de dispositivo vaginal com $1 \mathrm{~g}$ de $\mathrm{P}_{4}$. Dia 8 (D8): Aplicação do D-Cloprostenol Sódico (150 mg, IM), e 300 UI de Gonadotrofina Coriônica Equina (eCG). Dia 9 aplicação de $1 \mathrm{mg}$ IM de BE. Grupo 9D retirada do implante no de $\mathrm{P}_{4}$ dia 8 (D8). Grupo P4D9 retirada do implante de $\mathrm{P}_{4}$ no Dia 9 (D9).

A metodologia de avaliação seguiu o mesmo padrão do experimento um para todos os parâmetros avaliados.

\subsection{Experimento 3}

O experimento 3 foi realizado no mesmo local compreendido para o experimento dois e para tal, utilizou-se 88 fêmeas (Figura 1.4) compreendidas em primíparas, pluríparas e nulíparas, lactantes e não lactantes, entre dois e seis anos, com condição corporal, manejo alimentar e avaliação ginecológica, também semelhante ao experimento 2 . 


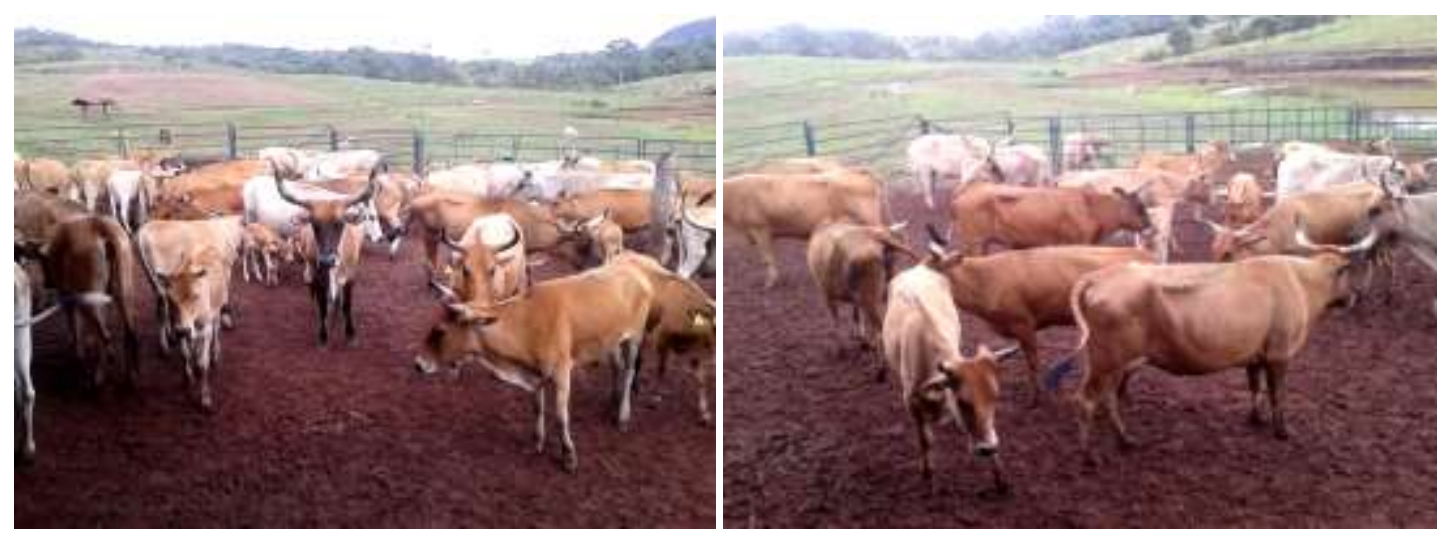

Figura 1.4. Fêmeas da Raça Curraleiro Pé-Duro que passaram pelo programa de IATF.

No grupo 8D ( $n=43)$,as fêmeas receberam um dispositivo intravaginal contendo $1 \mathrm{~g}$ de $\mathrm{P}_{4}$ que permaneceu durante oito dias e $2 \mathrm{mg}$ de BE IM no momento da inserção do dispositivo (Dia 0). Na retirada do dispositivo de $\mathrm{P}_{4}$ (D8) as fêmeas receberam 1 mg de BE, $150 \mu \mathrm{g}$ de D-cloprostenol Sódico e 300 UI de eCG IM, e foram inseminadas em tempo fixo num intervalo de 40/42 horas após a retirada do implante de $\mathrm{P}_{4}$.

Para o grupo P4D9, as fêmeas $(n=45)$, receberam um dispositivo intravaginal contendo $1 \mathrm{~g}$ de $\mathrm{P}_{4}$ que permaneceu por nove dias e $2 \mathrm{mg}$ IM de BE no momento da inserção do dispositivo (Dia 0). No D8 as vacas receberam por via IM, $150 \mu \mathrm{g}$ de D-cloprostenol Sódico e 300 UI de eCG. No D9, as vacas tiveram o implante de $\mathrm{P}_{4}$ removido e receberam IM $1 \mathrm{mg}$ de BE. As inseminações em tempo fixo ocorreram no período de 24/26 horas após a retirada do implante de $\mathrm{P}_{4}$. Os tratamentos diferiram quanto ao período a que esses animais ficaram expostos à $\mathrm{P}_{4}$ e ao dia de aplicação do BE (Figura 1.5). 

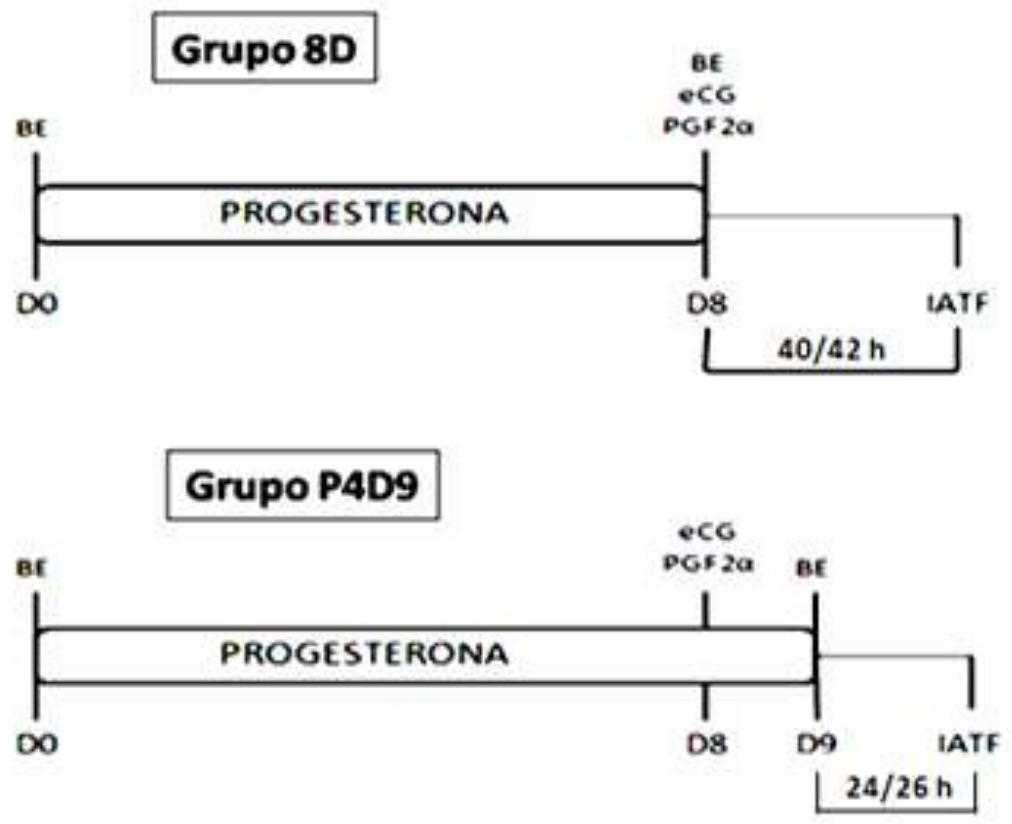

Figura 1.5. Delineamento experimental. Dia 0 (D0): administração de $2 \mathrm{mg}$ IM de BE e inserção de dispositivo vaginal com $1 \mathrm{~g}$ de $\mathrm{P}_{4}$. Dia 8 (D8): aplicação do D-Cloprostenol Sódico (150 mg, IM), $1 \mathrm{mg}$ de Benzoato de Estradiol (BE) e 300 UI de Gonadotrofina Coriônica Equina (eCG) Grupo 8D: retirada do implante de $\mathrm{P}_{4}$ no dia 8 (D8) e inseminadas em tempo fixo em 40/42h após a retirada do implante de $\mathrm{P}_{4}$. Grupo P4D9 retirado do implante de $\mathrm{P}_{4}$ e aplicação IM de $1 \mathrm{mg}$ de Benzoato de Estradiol (BE) no dia 9 (D9) e inseminadas em tempo fixo após 24/26h após a retirada do implante de $\mathrm{P}_{4}$. 


\section{Análise estatística}

As análises dos dados foram realizadas com o auxílio do software estatístico gratuito R Core Team 2013 (R: A language and environment for statistical computing. R Foundation for Statistical Computing, Vienna, Austria) adotando-se como nível de significância $\mathrm{P} \leq 0,05$. Os dados foram analisados quanto à normalidade pelo teste ShapiroWilk e não houve necessidade de transformação. O tamanho folicular foi analisado através do modelo linear generalizado (GLM) utilizando uma ANOVA e contraste para comparação entre os grupos. O tempo entre a retirada da P4 e ovulação e o volume do CL foram analisados também através da ANOVA e as médias comparadas pelo teste de Tukey. Dados demonstrados em porcentagem foram submetidos ao teste do chi-quadrado $\left(\chi^{2}\right)$ com correção de Yates. Os resultados estão apresentados em média \pm desvio padrão e \% (ovulações e taxa de gestação). O ajuste das curvas de desenvolvimento folicular foi realizado através do modelo de regressão linear, sendo a variável resposta o tamanho do folículo dominante, e a covariável os dias de avaliação e para avaliar a qualidade do ajuste da curva, utilizou-se como critério o coeficiente de determinação $\left(\mathrm{R}^{2}\right)$. 


\section{RESULTADOS}

\subsection{Experimento 1}

Não houve efeito dos tratamentos sobre o grupo e interação dia VS grupo $(\mathrm{P}>0,05)$ no desenvolvimento folicular após a colocação do implante de $\mathrm{P}_{4}$ e administração de $\mathrm{BE}$, apenas crescimento diário $(\mathrm{P}<0,05)$.

$\mathrm{Na}$ avaliação de dinâmica folicular, não houve diferença entre as curvas de crescimento folicular até porque o tratamento no D0 não diferiu e os grupos foram unidos em desenho único de curva de padrão de comportamento do FD após a colocação da $\mathrm{P}_{4}$ exógena e aplicação do BE (Figura 1.6), que, quando colocado na fórmula, a emergência começando com $4 \mathrm{~mm}$, percebeu-se que o reinício da onda folicular durante o tratamento se deu no dia 3,5 .

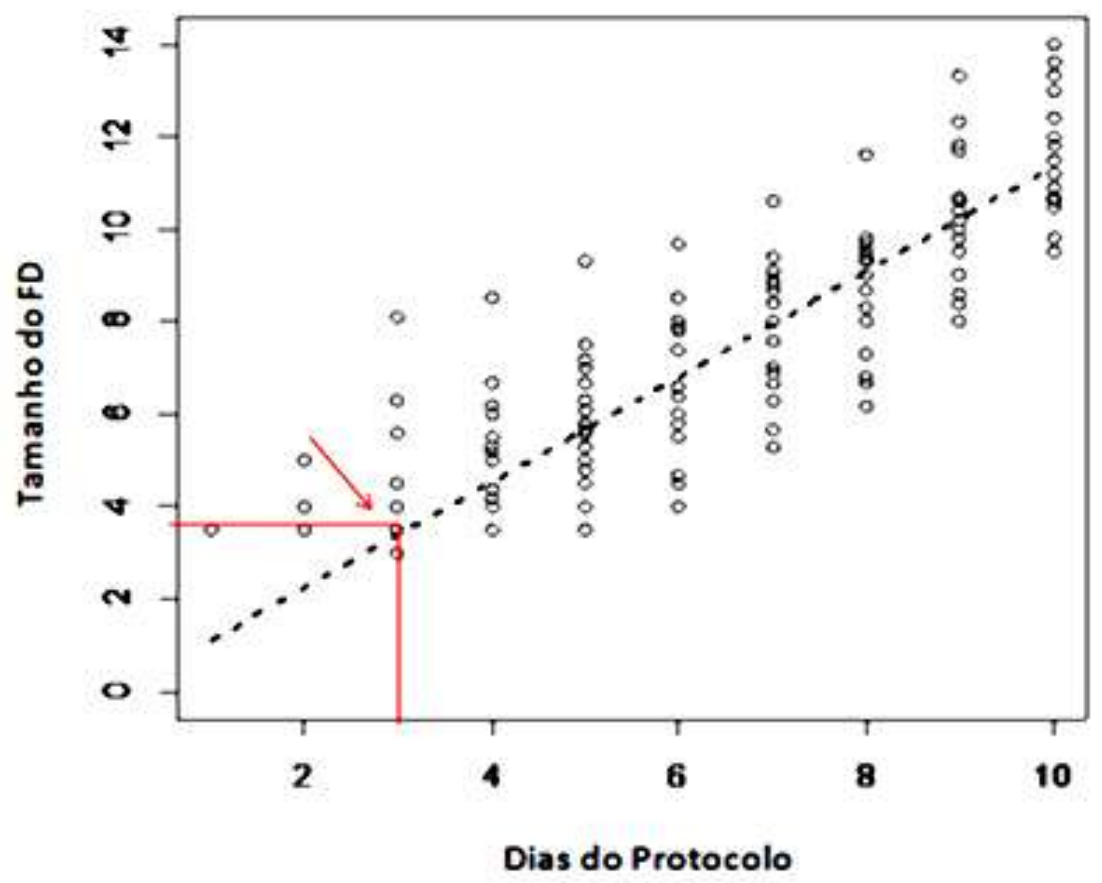

Figura 1.6. Padrão de comportamento do FD após a colocação da $\mathrm{P}_{4}$. FD - Folículo dominante. 
Das 12 fêmeas avaliadas para o tratamento 8D e 9D, uma e duas, respectivamente, não responderam aos protocolos de sincronização por apresentarem CL muito menor (em torno de $1.000 \mathrm{~mm}^{3}$ ) do que é considerado fisiológico para o dia 10 (4.000 a $5.000 \mathrm{~mm}^{3}$ ) pós ovulação, ou por terem folículo dominante menor que $7 \mathrm{~mm}$ no Dia 8 do tratamento. Os Grupos 8D e 9D levaram a uma taxa de sincronização do folículo dominante de $92 \%(11 / 12)$ e $83 \%(10 / 12)$ respectivamente $(\mathrm{P}>0,05)$ (Figura 1.7).

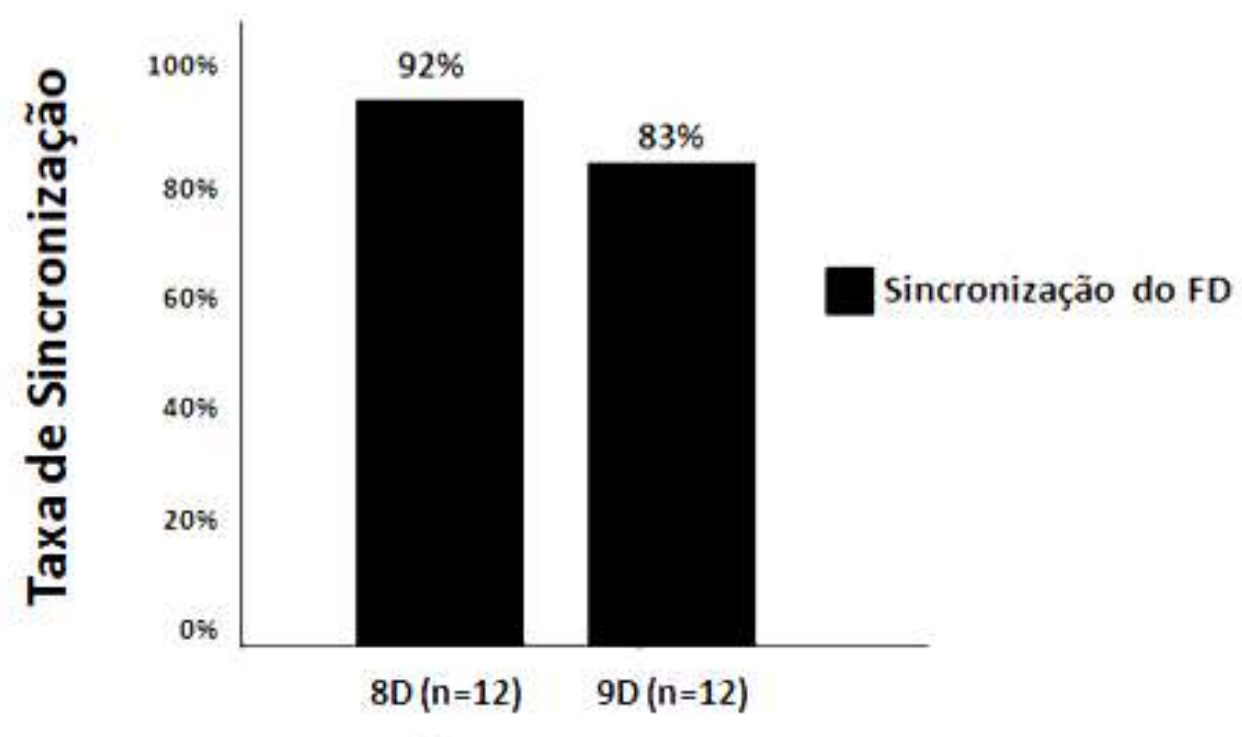

\section{Tratamentos}

Figura 1.7. Taxa de sincronização do FD para os tratamentos $8 D(n=12)$ e $9 D(n=12)(P>0,05)$.

FD - Folículo Dominante.

$\%$ - Valores apresentados em porcentagem para ambos os tratamentos.

$\mathrm{n}$ - Número de animais submetidos a cada tratamento.

A taxa de ovulação (TOV) foi de 73\% (8/11) e 100\% (10/10) para os Grupos 8D e 9D respectivamente (Figura 1.8). 


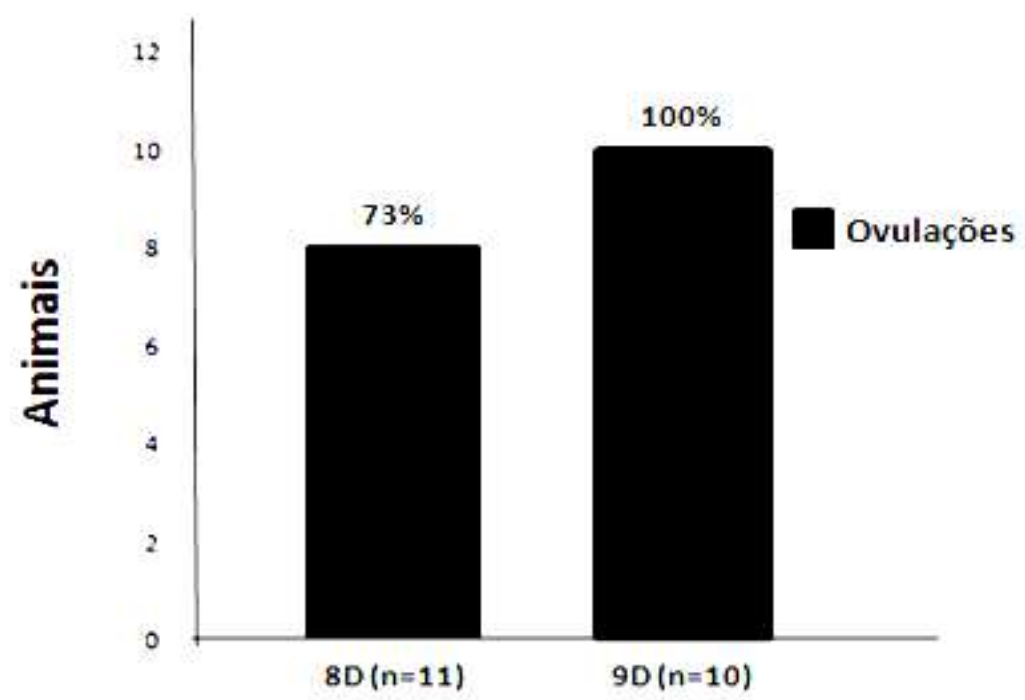

Tratamentos

Figura 1.8. Taxa de ovulação das fêmeas submetidas aos grupos $8 D(n=11)$ e 9D $(n=10)$. $\%$ - Valores apresentados em porcentagem para ambos os tratamentos. $\mathrm{n}$ - Número de animais submetidos a cada tratamento.

O tamanho do FD no D8 e no D9, o tamanho do FO e o volume do CL foram semelhantes entre os grupos $(\mathrm{P}>0,05)$. Os animais submetidos ao tratamento 8D apresentaram um período para ovulação mais precoce $(58 \pm 2 \mathrm{~h}$ vs $73,3 \pm 3 \mathrm{~h})$ do que os animais submetidos ao tratamento 9D $(\mathrm{P}<0,05)$ (Tabela 1).

Tabela 1 - Características foliculares e luteais (média \pm DP) observadas em fêmeas Curraleiras Pé-Duro.

\begin{tabular}{|c|c|c|}
\hline \multirow[b]{2}{*}{ Parâmetros } & \multicolumn{2}{|c|}{ Grupos } \\
\hline & Grupo 8D $(n=11)$ & Grupo 9D $(n=10)$ \\
\hline Tamanho Folículo D8 (mm) & $8,4 \pm 0,4$ & $8,6 \pm 0,4$ \\
\hline Tamanho Folículo D9 (mm) & $10 \pm 0,5$ & $10,6 \pm 0,5$ \\
\hline Tamanho FO (mm) & $11,5 \pm 0,5$ & $12,2 \pm 0,5$ \\
\hline $\begin{array}{l}\text { Tempo para Ovulação após a } \\
\text { Retirada da } \mathrm{P}_{4}(\mathrm{~h})\end{array}$ & $58 \pm 2^{\mathrm{a}}$ & $73 \pm 3^{b}$ \\
\hline Volume CL (mm³) & $4.239 \pm 521$ & $3.505 \pm 487$ \\
\hline
\end{tabular}

a,b Médias com letras diferentes na mesma linha diferem a um nível de significância de $\mathrm{P}<0,05$.

FD - Folículo dominante.

FO - Folículo Ovulatório.

$\mathrm{P}_{4}$ - Progesterona.

CL-Corpo lúteo. 


\subsection{Experimento 2}

Das 11 fêmeas avaliadas para o grupo P4D8, três foram excluídas da análise dos dados referentes ao experimento por apresentarem CL muito menor (em torno de 1.000 $\left.\mathrm{mm}^{3}\right)$ do que é considerado fisiológico para o dia $10\left(4.000\right.$ a $\left.5.000 \mathrm{~mm}^{3}\right)$ pós ovulação, ou por terem folículo dominante menor que $7 \mathrm{~mm}$ no dia 8 do tratamento, o que torna relevante o fato de que não houve eficácia na sincronização da nova onda folicular, para evitar que o resultado fosse mascarado

Os tratamentos 9D e P4D9 levaram a uma taxa de sincronização do folículo dominante de $72 \%(8 / 11)$ e $100 \%$ (11/11), respectivamente (figura 1.9).

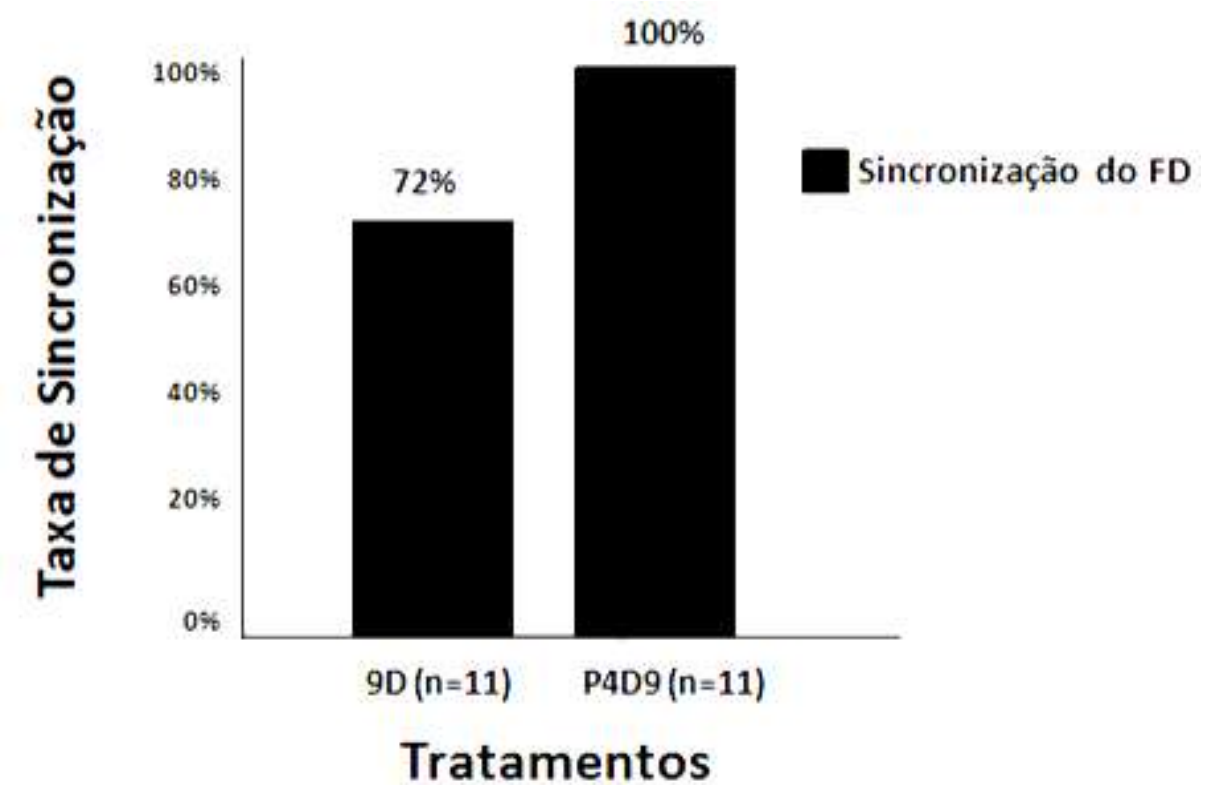

Figura 1.9. Taxa de sincronização do FD para os tratamentos 9D $(n=11)$ e P4D9 $(n=11)$.

FD - Folículo Dominante.

$\%$ - Valores apresentados em porcentagem para ambos os tratamentos.

$\mathrm{n}$ - Número de animais submetidos a cada tratamento.

A taxa de ovulação nos tratamentos P4D8 e P4D9 foi 87,5\% (7/8) e 91\% (10/11), respectivamente (figura 2). A estatística em cima destes dados não foi feita devido ao pequeno número de animais para este tipo de variável, o que levaria a um resultado de igualdade $(\mathrm{P}>0,05)$. 


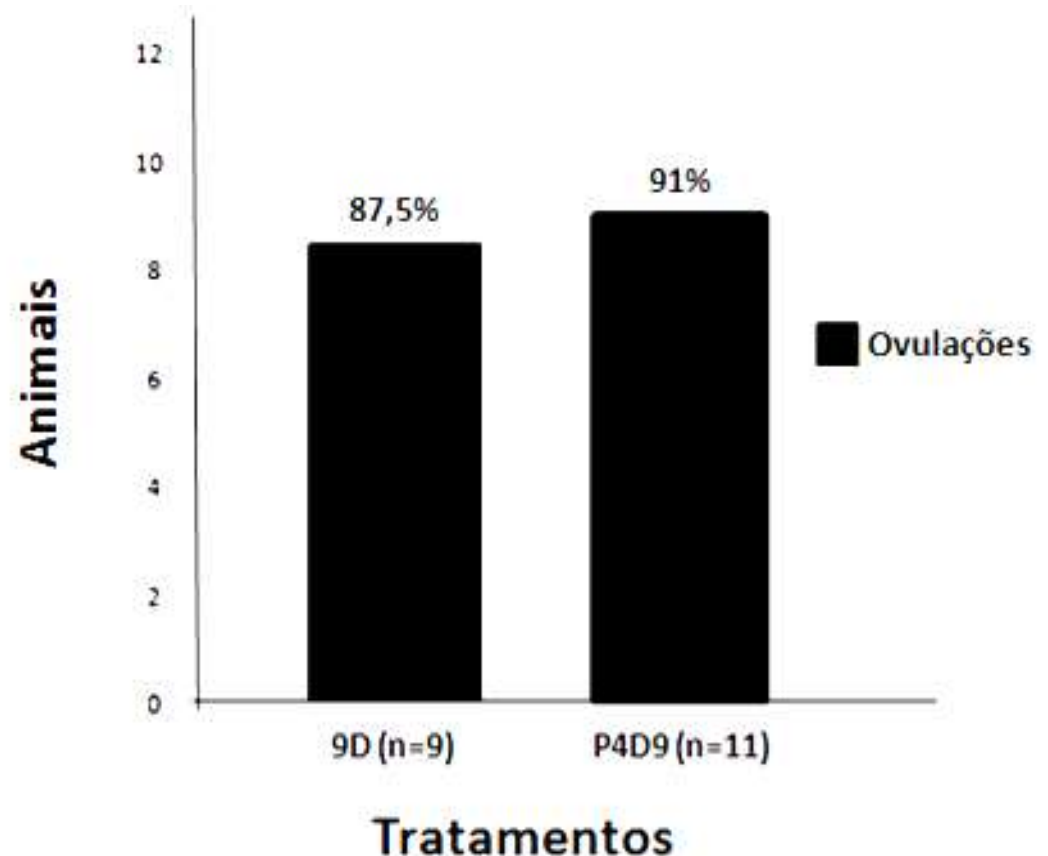

Figura 2. Taxa de ovulação das fêmeas submetidas aos tratamentos 9D (n=8) e P4D9 (n=11). $\%$ - Valores apresentados em porcentagem para ambos os tratamentos. $\mathrm{n}$ - Número de animais submetidos a cada tratamento.

A tabela 2 apresenta todos os dados referentes às características (média \pm DP) foliculares avaliadas mediante exames ultrassonográficos e análises estatísticas.

Tabela 2 - Características foliculares e luteais (média \pm DP) observadas em fêmeas Curraleiras Pé-Duro.

\begin{tabular}{lccc}
\hline & \multicolumn{2}{c}{ Grupos } \\
\cline { 2 - 3 } Parâmetros & $\begin{array}{c}\text { Grupo } \\
\text { 9D }(\mathbf{n}=\mathbf{8})\end{array}$ & & $\begin{array}{c}\text { Grupo } \\
\text { P4D9 (n=11) }\end{array}$ \\
\hline Tamanho Folículo D9 (mm) & $8,6 \pm 0,4$ & $8,6 \pm 0,4$ \\
${ } }$ & $10 \pm 0,4$ & $9,9 \pm 0,3$ \\
Tamanho FO (mm) & $11,7 \pm 0,4$ & $11,3 \pm 0,3$ \\
Tempo para Ovulação após a & $60 \pm 4$ & $70 \pm 4$ \\
Retirada da $\mathrm{P}_{4}(\mathrm{~h})$ & & \\
Volume CL (mm & $3.560 \pm 566$ & \\
\hline
\end{tabular}

Os dados estão apresentados como média \pm (DP).

FD - Folículo dominante.

FO - Folículo Ovulatório.

P4 - Progesterona.

CL - Corpo lúteo.

Não houve diferença no tamanho do FD no D8 ou D9 assim como no tamanho do FO, também, não houve efeito de grupo e interação grupo por dia $(\mathrm{P}>0,05)$ no 
desenvolvimento folicular, porém crescimento diário $(\mathrm{P}<0,001)$. Não houve diferença no tempo para ovulação, variação desta ao longo do tempo e volume luteal entre os grupos $(\mathrm{P}>0,05)$.

\subsection{Experimento 3}

A taxa de prenhes foi semelhante $(P>0,05)$ entre os grupos $8 D(n=43)$ e P4D9 $(\mathrm{n}=45)$ (Figura 2.1).

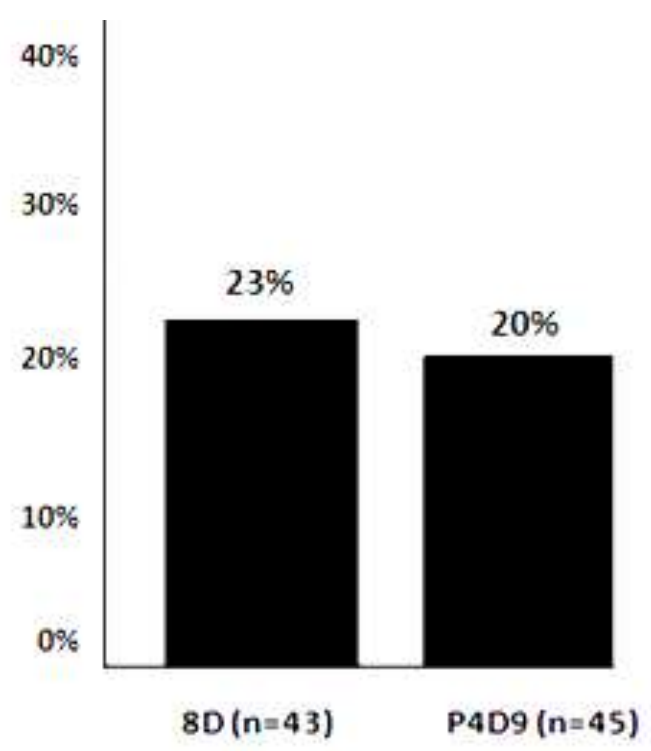

Figura 2.1. Taxa de gestação das fêmeas submetidas aos protocolos de inseminação artificial em tempo fixo para os grupos tratamentos 8D $(n=43)$ e P4D9 $(n=45)$.

$\%$ - Valores apresentados em porcentagem para ambos os tratamentos.

$\mathrm{n}$ - Número de animais submetidos a cada tratamento. 


\section{DISCUSSÃO}

Foi demonstrado por Bó et al (1993) que o tratamento com $\mathrm{E}_{2}$ no início dos protocolos de sincronização, é responsável pela supressão do crescimento folicular antral, e tal supressão se profunda ainda mais quando este é associado a um dispositivo liberador de $\mathrm{P}_{4}$, mediante a supressão de FSH via feedback negativo. Ainda, quando associado o $\mathrm{E}_{2}$ com a $\mathrm{P}_{4}$ no tratamento hormonal para sincronização nota-se a atresia do folículo dominante e em contrapartida a esse feito emerge uma nova onda de crescimento folicular, aproximadamente 3,5 a 4 dias após sua aplicação (Bó et al., 1995; Mapletoft, 2009).

$\mathrm{O}$ implante intravaginal de $\mathrm{P}_{4}$ mantém as concentrações plasmáticas de progesterona por determinado período de tempo, sendo que, sua retirada faz com que a $\mathrm{P}_{4}$ atinja níveis subluteais durante o final do tratamento, permitindo o aumento da frequência dos pulsos de LH, necessários ao crescimento folicular além de prevenir a atresia do FD (Fortune, 1993). O diâmetro do FD no dia da retirada do implante de $\mathrm{P}_{4}$ (D8) mostraram um resultado satisfatório na taxa de sincronização folicular uma vez que apresentaram tamanho superior a 8,0 mm (divergência folicular, Ginther et al., 1996), para ambos os grupos.

Os dados corroboraram com o encontrado por Tortorella et al, (2014), para fêmeas Curraleiras Pé-Duro $(8,1 \pm 1 \mathrm{~mm})$ para o FD no momento da divergência folicular. Tal feito anula a hipótese de que o implante de $\mathrm{P}_{4}$ por nove dias levaria a um crescimento do FD maior ao do grupo de animais expostos à $\mathrm{P}_{4}$ por oito dias, uma vez que, é sabido que bovinos Bos taurus, possuem FD maior que os animais Bos indicus no momento da divergência folicular, explicada em parte pelas concentrações de FSH e do fator de crescimento semelhante à insulina (IGF-1) nos diferentes grupos genéticos (Alvarez et al., 2000).

$\mathrm{Na}$ taxa de sincronização para o Experimento 1, observou-se uma maior sincronia para o grupo tratamento 8D (92\% VS 83\%), porém, quando avaliou-se o dados referentes à taxa de ovulação houve uma contrariedade entre os tratamentos, prevalecendo a ampla ovulação das fêmeas submetidas ao tratamento 9D (100\% VS 73\%), sugere-se o fato de as concentrações de $\mathrm{P}_{4}$ estarem ainda elevados quando o BE foi aplicado no mesmo dia da retirada do implante de $\mathrm{P}_{4}$, impedindo em partes a amplitude máxima dos pulsos de $\mathrm{LH}$ mediante feedback positivo ao GnRH na ovulação desse animais, uma vez que, a frequência 
de pulsos de GnRH e, consequentemente de LH é inversamente proporcional às concentrações de $\mathrm{P}_{4}$ circulante (Adams et al., 1992; Binelli et al. 2006), o que hipoteticamente não ocorreria com o CE, uma vez que, apresenta meia vida mais longa quando comparado ao BE.

Por outro lado, os tratamentos 9D e P4D9 do Experimento 2, levaram à uma taxa de sincronização do FD de $72 \%$ e $100 \%$ respectivamente, com um sincronismo maior para as fêmeas expostas por 9 dias ao tratamento com $\mathrm{P}_{4}$ exógena na tentativa de avaliar a eficácia do tratamento com maior tempo de exposição à $\mathrm{P}_{4}$ que a princípio mediante aplicação de eCG permitiria a formação de um folículo maior, com alta viabilidade fecundante e formação de um CL com produção de $\mathrm{P}_{4}$ aumentada, viabilizando assim, a manutenção de uma gestação (Baruselli et al., 2004). Foi perceptível que mesmo mediante aplicação do eCG, e expostas por mais 24 horas à $\mathrm{P}_{4}$, as fêmeas não apresentaram um crescimento diferenciado do FD. É sabido, que condição corporal afeta diretamente na resposta fisiológica positiva em programas de IATF, sendo que, as fêmeas Curraleiras Pé-Duro vêm de uma adaptação genética de décadas e, mesmo sofrendo restrição alimentar por determinado período, mantém seu ECC positivo (Bianchini et al. 2006).

Martinez et al., (2005) expõem que a determinação do tempo para ovulação após a retirada do implante de $\mathrm{P}_{4}$ está diretamente relacionada ao tipo, dose e horário da aplicação do estrógeno, uma vez que, tais aplicações no início e final do protocolo visa única e exclusivamente o sincronismo da ovulação. Para tamanho do FO não se constatou uma diferença estatística, contudo, o tamanho satisfatório para a ovulação relativamente foi alcançado para o Experimento 1 (Grupo $8 \mathrm{D}=11,5 \pm 0,5$ e Grupo 9D $=12,2 \pm 0,5$ ) e para o Experimento 2 (Grupo 9D = 11,7 \pm 0,4 e Grupo P4D9 = 11,3 \pm 0,3 ). Segundo Gimenes et al., (2008), a capacidade ovulatória é adquirida no momento em que o FD alcança $12 \mathrm{~mm}$ para fêmeas Bos taurus e $10 \mathrm{~mm}$ para Bos indicus.

Tortorella et al., (2014) ao avaliar as características foliculares de vacas Curraleiras Pé-Duro, na tentativa de descrever a dinâmica folicular ovariana durante o ciclo estral, constatou que o diâmetro do FO foi maior para as fêmeas que apresentaram um padrão de crescimento folicular de três ondas quando comparadas aos de duas ondas (FO; 13,01 \pm 0,3 mm VS 12,1 0,2 mm), com intervalo estro-ovulação de 24,8 a 26 horas, mesmo padrão observado na literatura (Wolfenson et al., 2004), uma vez que, para bovinos, o horário 
estipulado para a inseminação artificial é $12 \mathrm{~h}$ após a determinação do início do cio observado (Dransfield et al., 1998).

Com a administração do $\mathrm{E}_{2}, 24$ horas após a remoção do implante de $\mathrm{P}_{4}$, induzse um pico pré-ovulatório de LH entre 16 e 18 horas, após a aplicação, e tal feito culminará com a ovulação do FD em 24 a 32 horas mais tarde (Mapletoftet al., 2003), o que foi de acordo para o grupo tratamento $9 \mathrm{D}$, contudo, para o grupo tratamento $8 \mathrm{D}$ o BE aplicado no momento da retirada do implante de $\mathrm{P}_{4}$ antecipou o tempo para ovulação do FD apesar de apresentar um menor tamanho para o FO $(\mathrm{P} \leq 0,05)$.

Ainda, o tempo para ovulação após a retirada do implante de $\mathrm{P}_{4}$ diferiu entre os tratamento do Experimento $1(\mathrm{P}<0,05)$, apresentando precocidade para o grupo tratamento $8 \mathrm{D}$ comparado com o grupo 9D ( $58 \pm 2$ VS $73 \pm 3$ h) respectivamente. O resultado corrobora com o observado por Cutaia et al., (2003), que encontraram 68,2 horas, variando de 60-72 h, o tempo para ovulação após a retirada do implante de $\mathrm{P}_{4}$ em vacas cíclicas. Em outro estudo, com vacas Bos indidus x Bos taurus com cria ao pé, o tempo para ovulação após a retirada do implante com $\mathrm{P}_{4}$ ocorreu em 69,4 \pm 2 h (Marques et al., 2003), o mesmo constatado para os animais submetidos ao Experimento 2; (9D: $60 \pm 4$ VS P4D9: $70 \pm 4$ h) respectivamente.

Uma hipótese a ser levantada é quanto ao uso do CE no momento da retirada do implante de $\mathrm{P}_{4}$, na tentativa de aperfeiçoar e minimizar o número de manejos dessas fêmeas. Em protocolos convencionais o CE aplicado no momento da retirada do implante de $\mathrm{P}_{4}$, apresenta taxas de prenhez similares ao uso do BE 24 horas após a remoção do implante, promovendo a ovulação sincronizada em média 70 h após a remoção da $\mathrm{P}_{4}$, com IATF num intervalo de 48 a 58 horas após a aplicação do CE ou retirada da fonte de $\mathrm{P}_{4}$ (Martins et al., 2005).

A antiga hipótese de que o prolongamento da permanência da $\mathrm{P}_{4}$ que até então era de oito dias, para nove dias, poderia aumentar o tamanho do FD e consequentemente, as taxas de ovulação e prenhez em fêmeas Curraleiras Pé-Duro, não corroborou com o observado, uma vez que, as fêmeas que foram submetidas ao protocolo de maior período de exposição à $\mathrm{P}_{4}$ não apresentaram taxas de gestação satisfatórias e nem com um nível de significância maior aos animais do grupo controle (oito dias). Pereira et. al., (2014), avaliando o tempo de exposição à $\mathrm{P}_{4}$ exógena (8 VS 9 dias), em gado de leite, não obtiveram diferença nas taxas de gestação desses animais tanto aos $30(8$ dias $=45 \%$ e 9 dias $=42 \%)$ quanto aos 
60 dias pós IA ( 8 dias $=38 \%$ e 9 dias $=40 \%$ ), contudo, constataram que a perda embrionária apresentava menor ocorrência nos animais expostos à $\mathrm{P}_{4}$ por nove dias $(8$ dias $=14,7 \%$ e 9 $\operatorname{dias}=7,6 \%)$.

Quando comparados à média de 50\%, encontrada em programas de IATF para bovinos (Torres-Junior et al., 2014), os dados levantados para taxas de gestação das fêmeas Curraleiras Pé-Duro submetidas aos dois diferentes protocolos de IATF apresentaram resultados baixos (23\% e 20\%). Tal feito sugere que, o entendimento mais minucioso do complexo fisiológico responsável pelo dinamismo folicular das fêmeas localmente adaptadas da raça Curraleiro Pé-Duro deve amparar a elaboração e desenvolvimento de novos tratamentos, na tentativa de maximizar a eficiência desta na cadeia produtiva.

A escassez de foragens disponíveis em determinada época do ano leva os animais a um quadro de carência nutricional, fator que deve ser levado em consideração, uma vez que, o baixo índice nutricional provoca um retardamento no sistema endócrino e logo a um atraso a primeira ovulação pós-parto (Perrey et al., 1991), afetando a liberação de gonadotrofinas necessárias ao desenvolvimento folicular (Murphy et al., 1991). O resultado positivo dos protocolos hormonais está diretamente relacionado à condição sanitária e nutricional do rebanho (Sá Filho et al., 2013), sugerindo que, um levantamento individual de propriedade e padronização de rebanho seja feito na tentativa de validação de determinado protocolo para fins de IATF como o intuito de melhorar as taxas de gestação das fêmeas Curraleiras Pé-Duro.

A preservação dos recursos genéticos animais e a conservação das raças bovinas localmente adaptadas para uso futuro é tarefa minuciosa e importantíssima. As características de adaptação, resistência e rusticidade, tendem, num futuro bem próximo, a serem incorporadas à bovinocultura nacional. A produção do bovino Curraleiro Pé-Duro, no presente cenário de produção apresenta-se inviável, porém, seu potencial de produção para regiões geograficamente desfavoráveis por condições adversas de clima e a utilização da IATF como ferramenta de multiplicação merece uma atenção especial, na tentativa de inserção destes em nichos específicos de mercado ou até mesmo, futuramente, à pecuária comercial brasileira. 


\section{CONCLUSÃO}

O benzoato de estradiol quando aplicado no D8 do tratamento, mostrou-se bastante efetivo na sincronização, apesar de a taxa de ovulação e o tempo para ovulação terem sido menores se comparado às fêmeas que receberam o benzoato de estradiol no D9. O maior tempo de exposição à progesterona não favoreceu um maior crescimento do folículo dominante mesmo sob aplicação da gonadotrofina coriônica equina 24 horas antes a sua retirada, contudo apresentou excelentes taxas de sincronização e ovulação dos animais submetidos às avaliações. 


\section{REFERÊNCIAS BIBLIOGRÁFICAS}

ADAMS, G.P.; MATTERI, R.L.; GINTHER, O.J. The effect of progesterone on growth of ovarian follicles, emergence of follicular waves and circulating FSH in heifers.J. Reprod. Fertil. 95:627-640. 1992.

ANUALPEC. Anuário da pecuária brasileira. Comunicação FNP Argos, p. 368, 2012.

ALVAREZ, P.; SPICER, L.J.; CHASE, C.C. et al. Ovarian and endocrine characteristics during an estrous cycle in Angus, Brahman, and Senepol cows in a subtropical environment. Journal ofAnimal Science, v. 78, p. 1291-1302, 2000.

BARROS, M.H.D.; LOPES, P.S.; SIQUEIRA, J.B. et al. Criopreservação de sêmen de suínos da raça Piau submetido a três protocolos de congelamento. Revista Brasileira de Zootecnia, v. 41, n. 1806-9290, p. 914-922, 2012.

BARUSELLI, P.S.; REIS, E.L.; GONÇALVES, R.L; REVA, D. Manual prático de inseminação artificial em tempo fixo, Curitiba: Biogenesis do Brasil Ltda., p. 56, 2004.

BIANCHI, I.M.; SCHNEIDER, A.; RABASSA, V.R. et al. Efeito de diferentes métodos de congelamento, diluentes e tempos de resfriamento sobre a qualidade do sêmen suíno criopreservado. Acta Scientiae Veterinariae, v. 39, p. 7, 2011.

BINELLI, M.; IBIAPINA, B.T.; BISINOTTO, R.S. Bases fisiológicas, farmacológicas e endócrinas dos tratamentos de sincronização do crescimento folicular e da ovulação. Acta Scientiae Veterinariae, v.34, Sup. 1, p. 1-7, 2006.

BLANCH, E.; TOMÁS, C.; GRAHAM, J.K. et al. Response of boar sperm to the treatment with cholesterol-loaded cyclodextrins added prior to cryopreservation. Reprod Domest Anim, v. 47, n. 6, p. 959-64, Dec 2012. 
BÓ, G.A.; ADAMS, G.P.; CACCIA, M. et al. Ovarian follicular wave emergence after treatment with progestogen and estradiol in cattle. Anim. Reprod. Sci., v. 39, n.3, p.193204, 1995.

BÓ, G.A.; ADAMS, G.P.; NASSER. L.F. et al. Effect of estradiol valerate on ovarian follicles, emergence of follicular waves and circulating gonadotropins in heifers.Theriogenology, 40:225-239. 1993.

CAVALIERI, J.; RUBIO, I.; KINDER, J.E. et al. Synchronization of estrus and ovulation and associated endocrine changes in Bos indicus cows. Theriogenology, v.47, p.801-814, 1997.

CUTAIA, L.; TRIBULO, R.; BÓ, G.A. et al. Pregnancy rates in lactating beef cows treated with progesterone releasing devices, estradiol benzoate and equine chorionic gonadotropin (eCG). Theriogenology, v.59, p.216, 2003.

DORSEY, B.R.; KASIMANICKAM, R.; WHITTIER, W.D. et al. Effect of time from estrus to AI on pregnancy rates in estrous synchronized beef heifers. Animal Reproduction of Science, v.127, p. 1-6, 2011.

ERIKSSON, B.M.; VAZQUEZ, J.M.; MARTINEZ, E.A. et al. Effects of holding time during cooling and of type of package on plasma membrane integrity, motility and in vitro oocyte penetration ability of frozen-thawed boar spermatozoa. Theriogenology, v. 55, n. 8, p. 1593-605, May 12001.

FIGUEIREDO, R.A.; BARROS, C.M.; PINHEIRO, O.L. et al. Ovarian follicular dynamics in Nelore breed (Bosindicus) cattle. Theriogenology, v.47, p.1489-1505, 1997.

GIMENES, L.U.; SA FILHO, M.F.; CARVALHO, N.A. et al. Follicle deviation and ovulatory capacity in Bosindicusheifers. Theriogenology, v. 69, p. 852-858, 2008.

GINTHER, O.J.; WILTBANK, M.C.; FRICKE, P.M. et al. Selection of the dominant follicle in cattle.Biology of Reproduction, v. 55, p. 1187-1194, 1996.

GOMEZ-FERNANDEZ, J.; GÓMEZ-IZQUIERDO, E.; TOMÁS, C. et al. Effect of different monosaccharides and disaccharides on boar sperm quality after cryopreservation. Anim Reprod Sci, v. 133, n. 1-2, p. 109-16, Jul 2012.

HARRISON, R.A.; VICKERS, S.E. Use of fluorescent probes to assess membrane integrity in mammalian spermatozoa. J Reprod Fertil, v. 88, n. 1, p. 343-52, Jan 1990.

HUANG, J.S.; WU, C.S.; JIH, C.G. et al. Effect of addition of Rhodobacter sp. to activatedsludge reactors treating piggery wastewater. Water Res, v. 35, n. 16, p. 3867-75, Nov 2001.

KLINC, P.; RATH, D. Reduction of oxidative stress in bovine spermatozoa during flow cytometric sorting. Reprod Domest Anim, v. 42, n. 1, p. 63-7, Feb 2007. 
KONG, D.; SHANG, H.; GUO, K. et al. A study on optimizing the cryopreservation methods for Bama miniature pig semen. Exp Anim, v. 61, n. 5, p. 533-42, 2012.

MACEDO, G.G.; OLIVEIRA, M.; ROCHA, D.C. Synchronization of ovulation: how to mimic the reproductive physiology for best outcomes?Rev. Bras. Reprod. Anim., Belo Horizonte, v.39, n.1, p.41-46, jan./mar. 2015.

MAPLETOFT, R.J.; MARTÍNEZ, M.F.; COLAZO, M.G. et al. The use of controlled internal drug release devices for the regulation of bovine reproduction.Journal of Animal Science, Champaign, v. 81(E. Suppl. 2), p. E28-E36, 2003.

MAPLETOFT, R.J.; BÓ, G.A.; BARUSELLI, P.S. Control of ovarian function for assisted reproductive technologies in cattle. Anim. Reprod., v.6, n.1, p.114-124, Jan./Mar. 2009.

MARQUES, M.O.; REIS. E.L.; CAMPOS FILHO, E.P.; et al. Efeitos da administração de eCG e de Benzoato de Estradiol para sincronização da ovulação em vacas zebuínas no período pós-parto. In: Simpósio Internacional de Reproducción Animal, 5, 2003, Córdoba, Argentina. Anais... Córdoba: SIRA, 2003.

MARTINEZ, M.F.; KASTELIC, J.P.; BO, G.A. et al. Effects of estradiol and some of its esters on gonadotrophin release and ovarian follicular dynamics in CIDR-treated beef cattle. Animal Reproduction Science, v.86, p.37-52, 2005.

MAZUR, S.P.L.; CHU, E.H. A two-factor hypothesis of freezing injury evidence from Chinese hamster tissue-culture cells. Exp Cell Res, v. 71, p. 345-355, 1972.

MEDRANO, A.; HOLT, W.V.; WATSON, P.F. Controlled freezing studies on boar sperm cryopreservation. Andrologia, v. 41, n. 4, p. 246-50, Aug 2009.

MURPHY, M.G.; ENRIGHT, W.J.; CROWE, M.A. et al. Effect of dietary intake on pattern of growth of dominant follicles during the estrous cycle in beef heifers. Journal of Reproduction and Fertility. v.92,p.333-338, 1991.

PARRILLA, I.; DEL OLMO, D.; SIJSES, L. et al. Differences in the ability of spermatozoa from individual boar ejaculates to withstand different semen-processing techniques. Anim Reprod Sci, v. 132, n. 1-2, p. 66-73, May 2012.

PEREIRA, M.H.C.; RODRIGUES, A.D.P.; CARVALHO, R.J. et al. Increasing length of anestradiol and progesterone timed artificial insemination protocol decreases pregnancy losses in lactating dairy cows. J Dairy Sci, v.97, p.1454-1464, 2014.

PERRY, R.C.; CORAH, L.R.; COCHRAN, R.C. et al. Effect of hay quality, breed and ovarian development on onset of puberty and reproductive performance of beef heifers. J. Prod. Agric., v.4, n.1, p.13-18, 1991. 
SÁ FILHO, M.F.; PENTEADO, L.; REIS, E.L. et al. Timed artificial insemination early in the breeding season improves the reproductive performance of suckled beef cows. Theriogenology,v. 79, p. 625-632, 2013.

SELLES, E.; GADEA, J.; ROMAR, R. et al. Analysis of in vitro fertilizing capacity to evaluate the freezing procedures of boar semen and to predict the subsequent fertility. Reprod Domest Anim, v. 38, n. 1, p. 66-72, Feb 2003.

SILVA, M.A.; PEIXOTO, G.C.; CASTELO, T.S. et al. Cryopreservation of collared peccary (Pecari tajacu) semen using different freezing curves, straw sizes, and thawing rates. Cryobiology, v. 67, n. 1, p. 50-5, Aug 2013.

STOCK, J.; FORTUNE, J.E. Ovarian follicular dominance in cattle: relationship between prolonged growth of the ovulatory follicle and endocrine parameters. Endocrinology, v.132, p.1108-16, 1993.

TORTORELLA, R.D. Fisiologia e manipulação do ciclo estral dos bovinos da raça Curraleiro Pé-Duro. Brasília: Faculdade de Agronomia e Medicina Veterinária, Universidade de Brasília, 2014, 120 p. Tese (Doutorado em Ciências Animais) Faculdade de Agronomia e Medicina Veterinária da Universidade de Brasília, 2014.

TORRES-JÚNIOR, J.R.S.; PENTEADO, L.; SALES, J.N.S. et al. A comparison of two different esters of estradiol for the induction of ovulation in an estradiol plus progestinbased timed artificial insemination protocol for suckled Bos indicus beef cows. Anim. Reprod. Sci., v.151, p.9-14, 2014.

WALTER, B.M.; SAMPAIO, A.B., A vegetação da fazenda sucupira. 1998. 110p. Embrapa Recursos Genéticos e Biotecnologia, Brasília, 1998.

WOELDERS, H.; MATTHIJS, A.; ZUIDBERG, C.A. et al. Cryopreservation of boar semen: equilibrium freezing in the cryomicroscope and in straws. Theriogenology, v. 63, n. 2, p. 383-95, Jan 152005. 
CAPÍTULO 3 


\section{CONSIDERAÇÕES FINAIS}

Os dados encontrados neste trabalho servirão de base para o desenvolvimento de novas avaliações para fins de inseminação artificial em tempo fixo para bovinos Curraleiros Pé-Duro. Novas metodologias devem ser consideradas na validação dos protocolos, principalmente na questão de padronização das fêmeas que serão submetidas aos tratamentos finais de validação dos tratamentos.

O seguimento da prática de inseminar 12 horas após a detecção do estro para fêmeas bovinas deve amparar os novos estudos, uma vez que, dados referentes ao intervalo estro-ovulação de fêmeas Curraleiras Pé-Duro já foi determinado e não diferiu do padrão encontrado na literatura. Os tratamentos que apresentaram satisfatórias taxas de sincronização e ovulação devem ser reestudados e uma alternativa seria a visualização do estro e a partir disso a determinação do horário ideal para a IATF, sem risco de danos precoces ou tardios ao processo de capacitação espermática. 